\title{
A Coumarin-Based Analogue of Thiacetazone as Dual Covalent Inhibitor and Potential Fluorescent Label of HadA in Mycobacterium tuberculosis
}

Asma Farjallah ${ }^{\| \dagger \zeta}$, Laurent R. Chiarellil ${ }^{\| \S}$, Martin Forbak ${ }^{\| \ddagger}$, Giulia Degiacomi ${ }^{\S}$, Mathieu Danel $^{\dagger}$, Fernanda Goncalves ${ }^{\dagger}{ }^{\top}$, Chantal Carayon ${ }^{\top}$, Cendrine Seguin , Marco Fumagalli $^{\S}$, Monika Záhorszká ${ }^{\ddagger}$, Elodie Vega ${ }^{\perp}$, Souhir Abid ${ }^{\text {व }}$, Anna Grzegorzewicz ${ }^{\#}$, Mary Jackson" ${ }^{\#}$ Antonio Peixoto ${ }^{\perp}$, Jana Korduláková ${ }^{\star \ddagger}$, Maria Rosalia Pasca ${ }^{\star \S}$, Christian Lherbet ${ }^{\star{ }_{\top}}$ and Stefan Chassaing ${ }^{\star \dagger ¥}$

\section{Affiliations}

†ITAV, Université de Toulouse, CNRS USR3505, UPS, 1 place Pierre Potier, 31106 Toulouse Cedex 1, France.

${ }^{*}$ Laboratoire de Synthèse, Réactivité Organiques \& Catalyse (LASYROC), Institut de Chimie, CNRS-UMR7177, Université de Strasbourg, 4 rue Blaise Pascal, 67070 Strasbourg, France.

§Department of Biology and Biotechnology "Lazzaro Spallanzani", University of Pavia, via Ferrata 9, 27100 Pavia, Italy.

${ }^{\ddagger}$ Department of Biochemistry, Comenius University in Bratislava, Faculty of Natural Sciences, Mlynská Dolina, Ilkovičova 6, 84215 Bratislava, Slovakia.

${ }^{\perp}$ Institut de Pharmacologie et de Biologie Structurale, IPBS, Université de Toulouse, CNRS, UPS, 205 route de Narbonne, 31400 Toulouse, France.

'Laboratoire de Synthèse et Physico-Chimie de Molécules d'Intérêt Biologique (SPCMIB), Université Paul Sabatier-Toulouse III/ CNRS (UMR5068), 118 route de Narbonne, F-31062 Toulouse, France.

Laboratoire de Conception et Application de Molécules Bioactives (LCAMB), CNRSUMR7199, Université de Strasbourg, Faculté de Pharmacie, 74 route du Rhin, 67401 Illkirch, France.

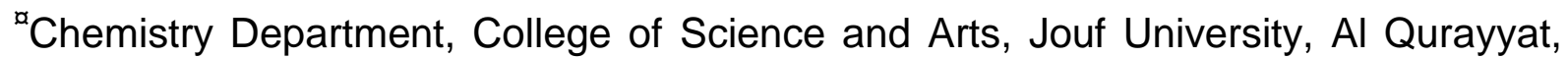
KSA.

'Laboratoire de Chimie Appliquée : Hétérocycles, Corps Gras et Polymères, Faculté des sciences de Sfax, Université de Sfax, Tunisie.

\#Mycobacteria Research Laboratories, Department of Microbiology, Immunology and Pathology, Colorado State University, Fort Collins, Colorado 80523-1682, United States.

Keywords: thiacetazone, coumarin, HadA, Mycobacterium tuberculosis, fluorescence 


\section{Authors Information}

Corresponding authors:

*E-mail: jana.kordulakova@uniba.sk

E-mail: mariarosalia.pasca@unipv.it

`E-mail: Iherbet@chimie.ups-tlse.fr

*E-mail: chassaing@unistra.fr

\section{ORCID}

Jana Kordulakova: 0000-0003-2834-0165

Maria Rosalia Pasca: 0000-0002-8906-4937

Christian Lherbet: 0000-0001-5427-5040

Stefan Chassaing: 0000-0001-5842-5288

\| The authors (A.F., L.R.C. and M.F.) contributed equally to this work. 


\section{ABSTRACT}

A novel coumarin-based molecule, designed as a fluorescent surrogate of a thiacetazone-derived antitubercular agent, was quickly and easily synthesized from readily available starting materials. This small molecule, coined as Coum-TAC, exhibited a combination of appropriate physicochemical and biological properties, including resistance towards hydrolysis and excellent antitubercular efficiency similar to that of well-known thiacetazone derivatives, as well as efficient covalent labeling of HadA, a relevant therapeutic target to combat Mycobacterium tuberculosis. More remarkably, Coum-TAC was successfully implemented as an imaging probe that is capable of labeling Mycobacterium tuberculosis in a selective manner, with an enrichment at the level of the poles, thus giving for the first time relevant insights about the polar localization of HadA in the mycobacteria. 


\section{INTRODUCTION}

Despite being one of the ancient and deadliest diseases affecting mankind, tuberculosis (TB) still is today a major health burden by being the leading cause of mortality due to an infectious disease worldwide. ${ }^{1}$ In actual fact, Mycobacterium tuberculosis (M.tb), the prime causative agent of TB, is nowadays infecting more than one-quarter of the world's population, with no fewer than 10 million new cases and 1.5 million deaths per year. The main obstacle to TB control is the emergence of $M$.tb strains that exhibit resistance to the frontline anti-TB drugs such as isoniazid (INH), rifampicin (RIF), ethambutol (EMB) and pyrazinamide (PYR). ${ }^{1,2}$ As these M.tb drugresistant strains are spreading further at an alarming rate, there is an urgent need for the development of novel effective drugs and/or therapeutic targets to combat this scourge.

Currently, most of efficient anti-TB strategies take advantage of the unique cell wall composition of M.tb which is particularly rich in lipids. It is indeed well established that mycobacteria's ability to survive is directly dependent on the integrity of its outer membrane called mycomembrane. ${ }^{3}$ The unique mycomembrane composition is due to the presence of specific fatty acids, namely mycolic acids (MAs), as major lipid components which are synthesized by two types of fatty acid-synthase system (FAS), i.e. FAS-I and FAS-II (Figure 1).

Among the FAS-II, four enzymes operate in tandem in each cycle of elongation. In particular, the third step of the fatty acid elongation is promoted by $\beta$-hydroxyacylACP dehydratase complex (HadABC) via dehydration of $\beta$-hydroxyacyl-ACP to trans2-enoyl-ACP, ${ }^{4} \mathrm{HadA}$ and HadC being the substrate binding subunits and HadB the catalytic subunit. Of significance is that the HadABC knock-out mutant in M.tb proved to be not viable ${ }^{3}$ and further studies showed that HadA and HadB are essential for cell viability but not $\mathrm{HadC}^{5}$. 


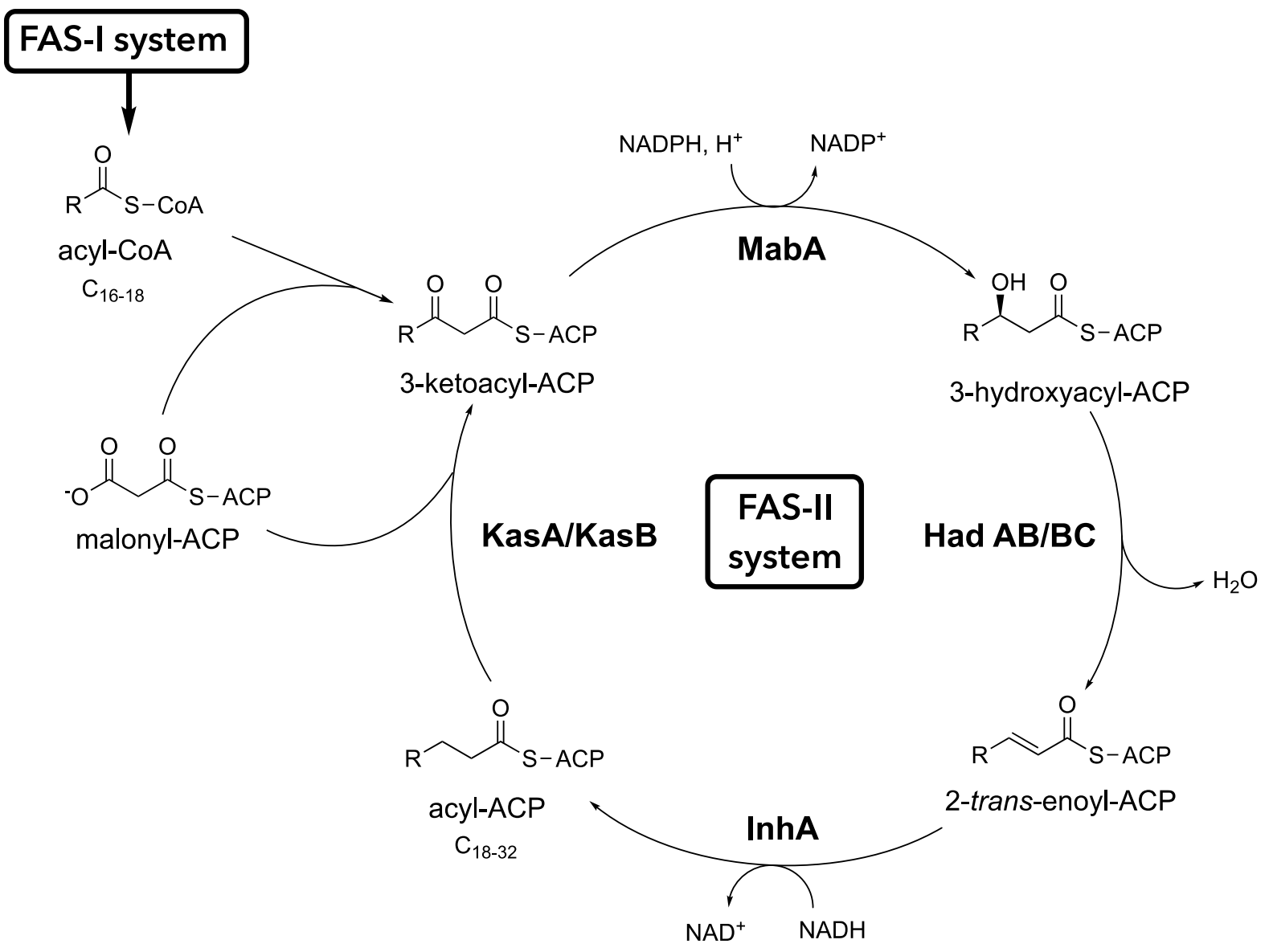

Figure 1. The FAS-II pathway in M.tb with enzymes in bold.

Thus, these results make Had proteins, especially $\mathrm{HadA}$ and $\mathrm{HadB}$, relevant therapeutic targets to combat M.tb. Among the existing compounds targeting Had proteins, thiacetazone (TAC) is an anti-TB drug that had been widely used in combination with the prodrug isoniazid (INH) in South America and Africa (Scheme 1). TAC is a prodrug that has to be activated by the mycobacterial monoxygenase EthA that is also able to activate the two other well-known anti-TB drugs ethionamide (ETH) and isoxyl (ISO). ${ }^{6,7,8,9}$ Activated TAC and ISO have been shown to inhibit the dehydration step of the FAS-II system pathway, while ETH after activation acts as an inhibitor of enoyl-ACP reductase InhA. ${ }^{10}$ Biochemical and proteomic evidences established that TAC specifically and covalently reacts with a cysteine residue (i.e., Cys61) of HadA subunit of the dehydratase (Scheme 1). ${ }^{11}$ Unfortunately, attempts to characterize the $\mathrm{HadA}^{\mathrm{WT}}$-drug complexes have failed so far due to the presence of Cys 105 able to displace the drug to afford a disulfide bridge Cys61-Cys105, possibly formed either in the mycobacteria or during the isolation of the HadA-drug complexes. 


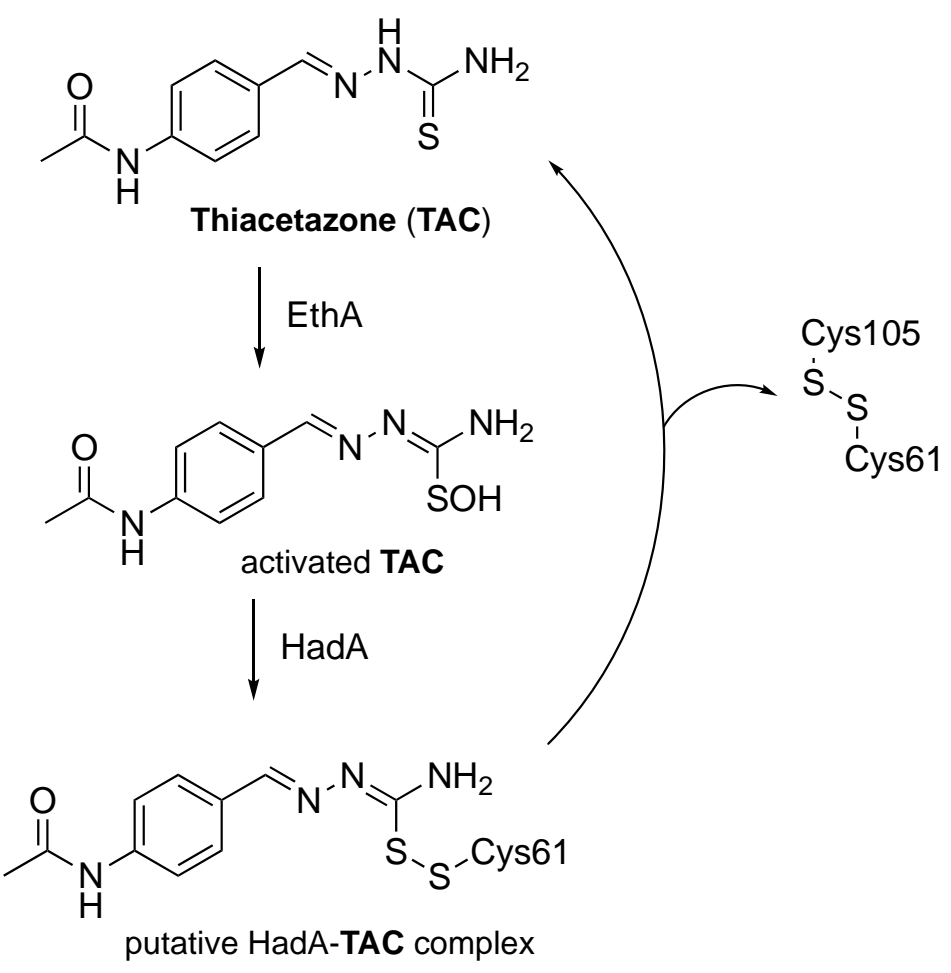

Scheme 1. Thiacetazone (TAC): structure and suggested mechanism of HadA inactivation.

In that context, there is an actual need to develop effective tools for increasing knowledge about HadA due to its relevance as therapeutic target. The localization of HadA in the mycobacteria would be a first step forward. Despite intensive efforts to localize proteins from the FAS-II system in the mycobacteria, the localization of HadA is indeed still unknown, unlike other FAS-II proteins, including MabA, InhA, KasA and $\mathrm{KasB}$, which were localized in the same region at the poles (Figure 1). ${ }^{12}$ To achieve this goal, we intend to provide a novel chemical tool enabling the imaging and the identification of HadA in the mycobacteria.

Herein, we precisely report a structurally-simple and easy-to-prepare probe able to play a dual role of covalent inhibition and imaging. The present work thus details the rational design and straightforward synthesis of the envisaged probe, as well as the evaluation of its potential not only as an efficient covalent inhibitor of $\operatorname{HadA}$ and MAs biosynthesis in mycobacteria, but also as a useful fluorescent probe in M.tb.

\section{RESULTS AND DISCUSSION}

Design and synthesis of Coum-TAC. As depicted in Figure 2, the design of the envisaged probe (i.e., Coum-TAC) relied on the construction of a covalent conjugate of a known anti-TB agent with a fluorescent moiety (Figure 2). To find a judicious 
anti-TB agent, we focused our attention on already reported TAC analogues, bearing thus the thiocarbazone group prone to target HadA protein (Scheme 2). In fact, various TAC analogues have been reported in the literature as efficient anti-TB agents. $^{12-14}$ While most of the reported analogues feature distinct substitution patterns on the aryl ring of TAC, ${ }^{13,14}$ some heteroaryl (i.e., thiophenyl, pyridinyl, quinoleinyl ...) derivatives were also found to exhibit good to excellent activities against $M . t b^{15}$. Regarding these data, we selected the thiophenyl-based TAC analogue (right hand blue structure in Figure 2) to be conjugated with a fluorescent moiety. This choice was motivated not only by the excellent anti-TB activity of this analogue (i.e., MIC $(\mathrm{H} 37 \mathrm{Rv})<1 \mu \mathrm{g} / \mathrm{mL})$, but also by its ease of chemical incorporation in the targeted Coum-TAC probe. As fluorescent moiety, our choice went to the coumarin scaffold, a popular heterocyclic chromophore responsible for the fluorescence of numerous compounds of imaging relevance. ${ }^{16}$ More particularly, 7-(N,N)-diethylaminocoumarin, commonly referred to as coumarin 466 (left hand red structure in Figure 2), was selected due to its well-known photophysical properties. ${ }^{17}$ Of note, the coumarin skeleton is also a privileged scaffold in life sciences due its presence in numerous biologically-relevant natural or synthetic products. ${ }^{18}$ The range of biological activities of coumarins is indeed quite broad, coumarin-based compounds having been reported in the literature as antitumor, ${ }^{19}$ antidepressant, ${ }^{20}$ anti-Alzheimer, ${ }^{21}$ anti-inflammatory, ${ }^{22}$ antioxidant, ${ }^{23}$ anti-HIV ${ }^{24}$ but also as anti-TB agents $^{25}$.

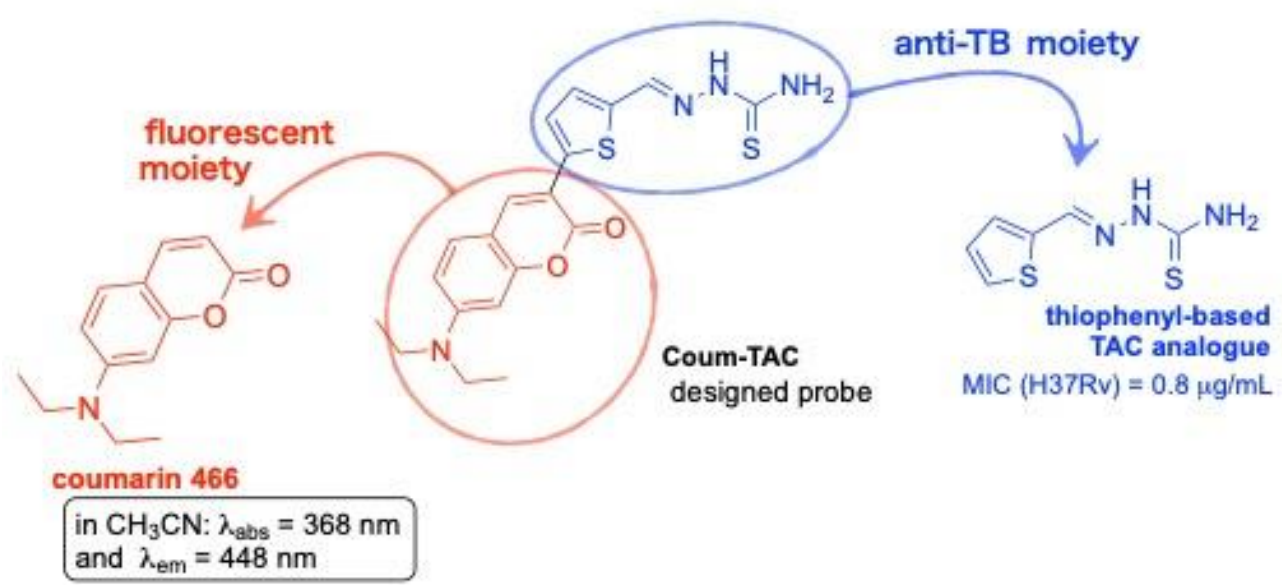

Figure 2. Coum-TAC probe as a covalent conjugate of an anti-TB agent (in blue, see ref 14 for details) with a fluorescent moiety (in red).

We next planned the synthesis of Coum-TAC which was successfully achieved in four steps from 4-(N,N)-diethylaminosalicylaldehyde and 2-thiopheneacetonitrile as 
commercially available starting materials (Scheme 2). The two first steps allowed the construction of the required coumarin moiety via base-catalyzed cyclocondensation of 4-(N,N)-diethylaminosalicylaldehyde with 2-thiopheneacetonitrile followed by acidmediated hydrolysis of the iminocoumarin intermediate 1 . The so-formed coumarin 2 equipped with a thiophenyl residue was next subjected to Vilsmeier-Haack conditions to furnish formylated coumarin 3. Coum-TAC was finally obtained by condensation between 3 and thiosemicarbazide in refluxing ethanol. Noteworthy are the efficient, straightforward and easy-to-synthesize features of this four-steps sequence without the need for any chromatographic purification step.

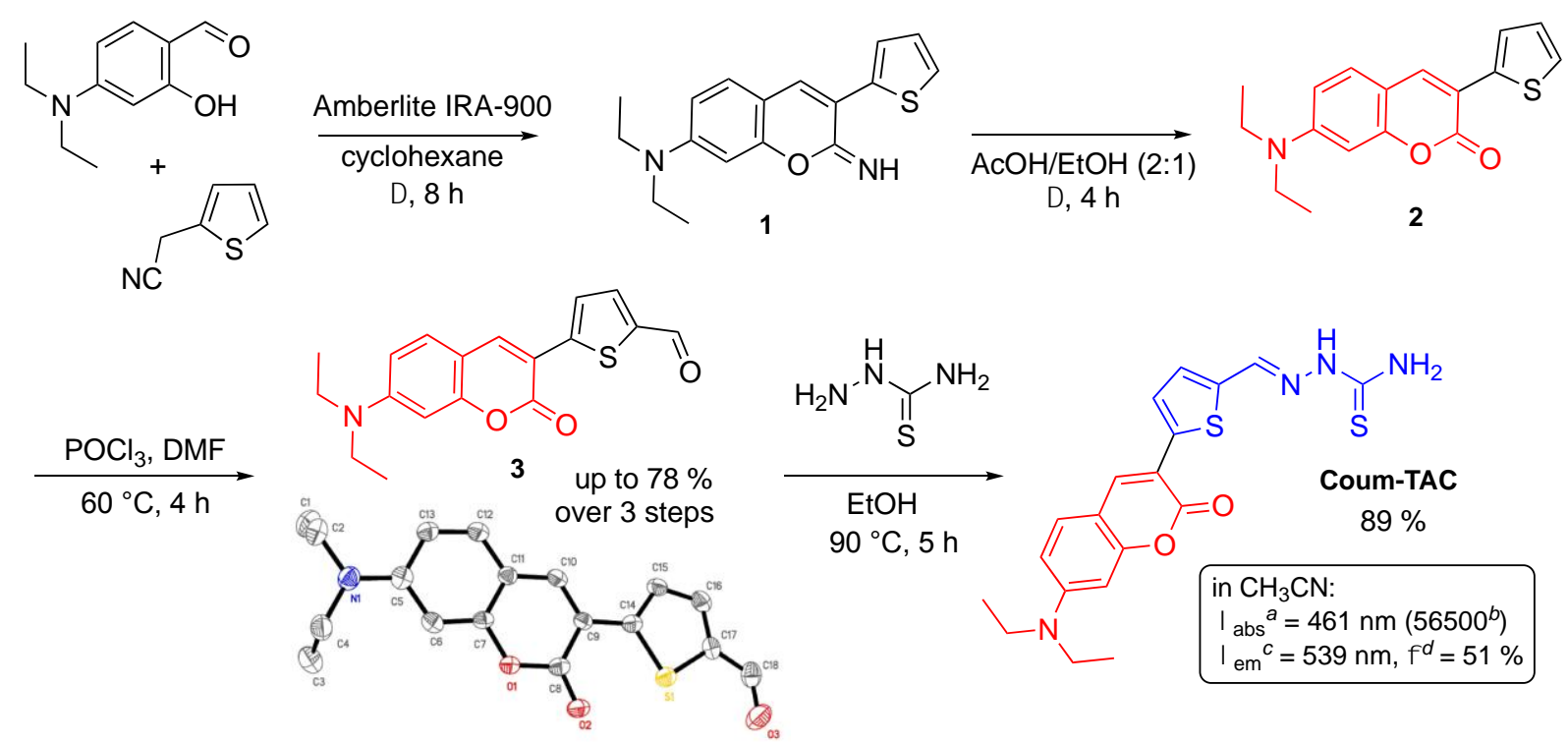

Scheme 2. Synthesis and photophysical properties of Coum-TAC. ${ }^{a}$ Maximum absorption wavelength in $\mathrm{nm} .{ }^{b}$ Molar extinction coefficient in $\mathrm{M}^{-1} \mathrm{~cm}^{-1}$. ${ }^{c}$ Maximum emission wavelength in $\mathrm{nm}$. ${ }^{d}$ Fluorescence quantum yield at $461 \mathrm{~nm}$.

Stability and photophysical evaluation of Coum-TAC. Additional properties of Coum-TAC were required before moving forward with its biological profile.

First, we evaluated the stability of Coum-TAC under aqueous conditions in order to confirm the robustness of its hydrazone function towards hydrolysis. This data of robustness will provide relevant information about the stability of Coum-TAC under the conditions applied thereafter in the course of its biological evaluation. Hence, its stability was evaluated for 21 days at $37{ }^{\circ} \mathrm{C}$ in a mixture $\mathrm{CH}_{3} \mathrm{CN} / \mathrm{H}_{2} \mathrm{O}$ 8:2 and monitored by LC/MS (Figure $\mathbf{S 1}$ in the Supporting Information). Under such conditions, Coum-TAC exhibited sufficient resistance towards hydrolysis (less than 5 
$\%$ decrease over the investigated period), thus revealing an adequate stability profile of Coum-TAC for its biological evaluation, which is to follow.

For imaging purposes, we also evaluated photophysical properties of Coum-TAC by means of UV-vis and fluorescence spectroscopies. Shifting from coumarin 466 to Coum-TAC led, as expected, to a substantial red shift at the apex of both absorption and emission peaks (maximum wavelengths increase of $80 \mathrm{~nm}$ and $91 \mathrm{~nm}$ in acetonitrile, respectively). Coum-TAC indeed exhibits a strong and sharp absorption band at $461 \mathrm{~nm}$ and a strong emission band at $539 \mathrm{~nm}$, thus revealing a large Stokes shift (ie. $78 \mathrm{~nm}$ ). These data make Coum-TAC a fluorescent candidate suited to imaging experiments detailed later in this study.

Evaluation of the anti-TB activity of Coum-TAC. The antitubercular activity of Coum-TAC was determined against M.tb H37Rv (entry 1, Table 1), showing a MIC of $0.5 \mu \mathrm{g} / \mathrm{mL}$ very similar to MIC of various TAC analogues found in the literature ${ }^{12,13}$ and more specifically to that of the thiophenyl-based TAC analogue selected as antiTB moiety of Coum-TAC (i.e., with a reported MIC (H37Rv) of $0.8 \mu \mathrm{g} / \mathrm{mL}$ ) (Figure $2)^{14}$. As a control, no antimycobacterial effect was observed for the synthetic precursor 3 of Coum-TAC, thus revealing the crucial effect of the thiocarbazone group. MIC of Coum-TAC was also determined for M. smegmatis $\mathrm{mc}^{2} 155$ strain. As expected, ${ }^{26}$ the MIC in $M$. smegmatis is > $256 \mu \mathrm{g} / \mathrm{mL}$, thus revealing that $M$. smegmatis strain is resistant to Coum-TAC as for TAC. As a control, INH presents a MIC in $M$. smegmatis of $16 \mu \mathrm{g} / \mathrm{mL}$. To investigate whether Coum-TAC has a bacteriostatic or cidal activity against M.tb H37Rv, kill kinetics were performed comparing the activity of Coum-TAC with that of TAC. M.tb cultures were exposed at MIC concentration ( 0.5 and $1 \mu \mathrm{g} / \mathrm{ml}$, respectively) and 10-fold MIC values, and viability was measured. TAC has a bacteriostatic effect on M.tb cultures, as reported literature, ${ }^{7}$ and cultures treated with Coum-TAC also showed a similar bacteriostatic activity (Figure $\mathbf{S} 2$ in the Supporting Information).

Consequently, in order to study the mechanism of action of Coum-TAC, a panel of nine M.tb mutants already available and harboring different mutations in genes encoding for drug targets (NTB1, DR1, 88.1, 88.7), activators (53.3 and 81.10) and inactivator (Ty1) was used. More specifically: i) 53.3 mutant harbours a mutation in $R v 2466 c$ coding for the activator of the TP053 thienopyrimidine (entry 2, Table 1), ${ }^{26}$ ii) NTB1 presents a mutation in dprE1, coding for the benzothiazinone target (entry 
3), ${ }^{27}$ iii) DR1 mutant harbours a mutation in $m m p L 3$, which codes for the cellular target of BM212 and other compounds (entry 4), ${ }^{28}$ iv) TY1 has a mutation in Rv3405c coding for the repressor of Rv3406, an enzyme inactivating the Ty38c carboxyquinoxaline (entry 5), ${ }^{29}$ v) 88.1 mutant harbours a mutation in coaA coding for PanK which is the target of thiphenecarboxamides (entry 6$),{ }^{30}$ vi) 88.7 presents a mutation in pyrG coding for the CTP synthetase which is the second target of thiophenecarboxamides (entry 7), ${ }^{31}$ vii) 81.10 compound has a mutation in ethA coding for the activator of TAC, ethionamide (ETH) and isoxyl (ISO) (entry 8$)^{31}$. Finally, Coum-TAC was evaluated for its activity against two M.tb multi-drug resistant clinical isolates $\mathrm{Cl} 1$ and $\mathrm{Cl} 2$ (entries 9-10). ${ }^{32}$

As expected, 81.10 mutant (mutated in ethA gene) and the two clinical strains, i.e. $\mathrm{Cl} 1$ and $\mathrm{Cl} 2$ (also resistant to ETH), were resistant to Coum-TAC, suggesting that this compound could be activated by EthA similarly to TAC (entries 8-10). All the other mutants are sensitive to Coum-TAC, thus highlighting that their mutations are not linked to the mechanism of action/resistance of this compound.

Table 1. Activity of Coum-TAC against M.tb H37Rv and several drug-resistant strains

\begin{tabular}{|c|c|c|c|}
\hline Entry & M.tb strains & $\begin{array}{c}\text { MIC }(\mu \mathrm{g} / \mathrm{mL}) \\
\text { Coum-TAC }\end{array}$ & References \\
\hline 1 & WT H37Rv & 0.5 & \\
\hline 2 & $53.3(R v 2466 c$, W28S) & 0.5 & 27 \\
\hline 3 & NTB1 (DprE1, G387S) & 0.5 & 28 \\
\hline 4 & DR1 (MmpL3, V681I) & 0.5 & 29 \\
\hline 5 & Ty1 (Rv3405c, c190t) & 0.5 & 30 \\
\hline 6 & $88.1($ CoaA, Q207R) & 0.5 & 31 \\
\hline 7 & 88.7 (pyrG, V186G) & 0.5 & 32 \\
\hline 8 & $81.10($ EthA, $\Delta 1109-37)$ & $>20$ & 26 \\
\hline 9 & $\mathrm{Cl}^{\mathrm{a}-c}$ & $>20$ & 33 \\
\hline 10 & $\mathrm{Cl} 2^{a-c}$ & $>20$ & 32 \\
\hline
\end{tabular}

${ }^{a}$ Drug resistance profiles of $M$.tb clinical isolates $(\mathrm{Cl})$ : Cl1 resistant to STR, INH, RIF, EMB, ETH / Cl2 resistant to STR, INH, RIF, EMB, ETH, PYR, capreomycin).

${ }^{b}$ With STR: streptomycin, INH: isoniazid, RIF: rifampicin, EMB: ethambutol, ETH: ethionamide, PYR: pyrazinamide.

${ }^{c}$ For structures of INH, RIF, EMB and ETH, see Figure 1.

Activation of Coum-TAC by EthA. To further confirm the role of EthA in Coum-TAC activation, the ability of the enzyme to metabolize the compound was investigated. Using a direct spectrophotometric assay, which measures the decrease in absorbance of the NADPH cofactor during the catalysis, we performed a steady state kinetic analysis vs both TAC and Coum-TAC (Figure 3), demonstrating that Coum- 
TAC is effectively a substrate of EthA. The enzyme showed kinetic parameters for TAC $\left(k_{c a t}=4.83 \pm 0.7 \mathrm{~min}^{-1} ; \mathrm{K}_{m}=0.153 \pm 0.011 \mathrm{mM}\right)$ in accordance with those previously reported. ${ }^{6}$ The $k_{\text {cat }}$ value for Coum-TAC $\left(0.72 \pm 0.17 \mathrm{~min}^{-1}\right)$, was lower than the one for TAC, but the affinity was about 10 fold higher with a $K_{m}$ of $0.016 \pm$ $0.002 \mathrm{mM}$. Thus, EthA shows a similar specificity towards both substrates with $k_{\text {cat }} / K_{m}$ of $45.0 \pm 6.2 \mathrm{~min}^{-1} \mathrm{mM}^{-1}$ for Coum-TAC vs $31.5 \pm 7.6 \mathrm{~min}^{-1} \mathrm{mM}^{-1}$ for TAC.

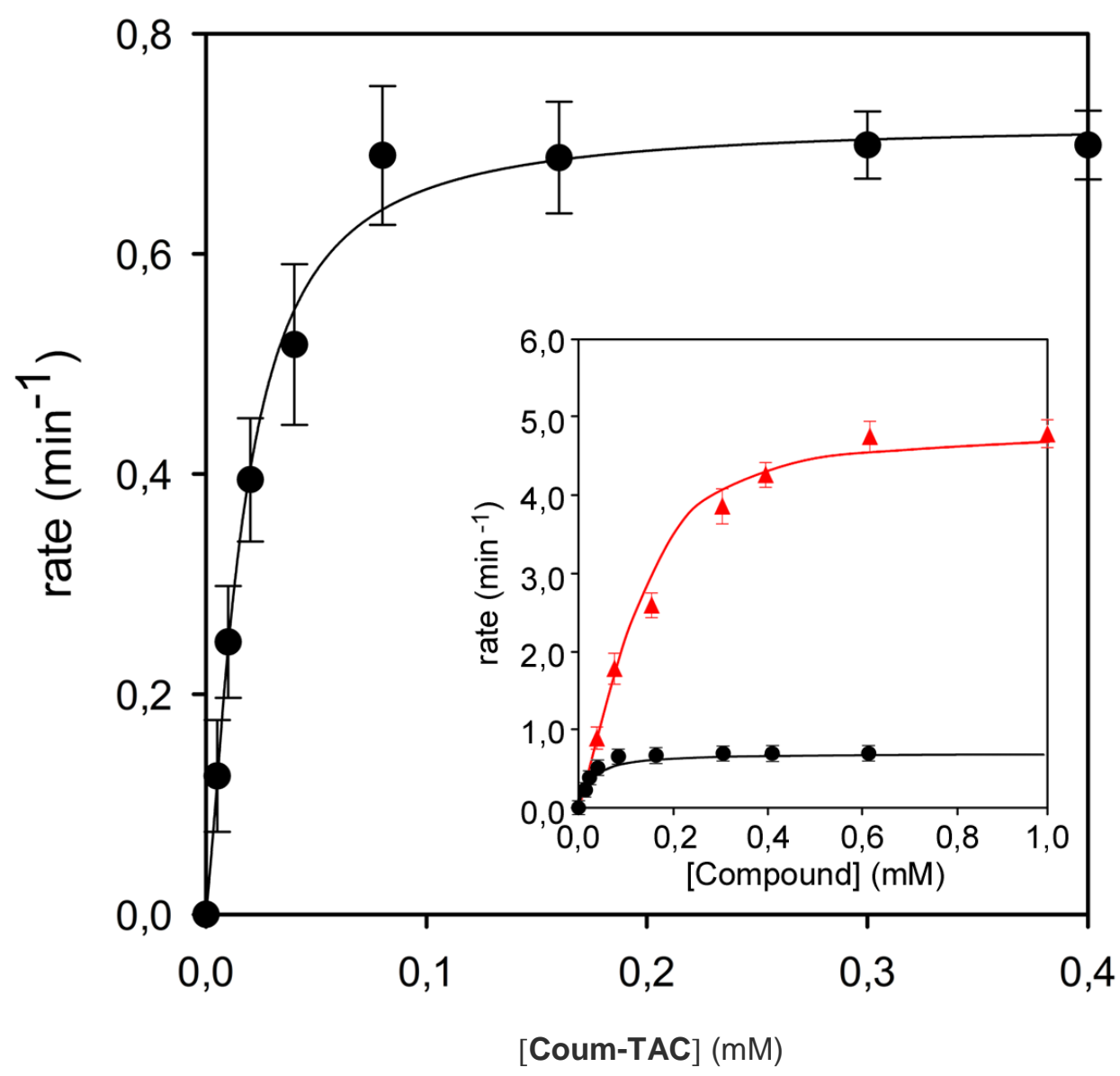

Figure 3. Steady-state kinetics of EthA as a function of Coum-TAC as a substrate. Data are mean \pm $\mathrm{SD}$ of at least three independent determinations. In the inset the comparison between the steady-state kinetics of TAC (red curve) vs Coum-TAC (black curve) is reported.

Inhibition of the synthesis of mycolic acids in M.tb H37Ra by Coum-TAC. To investigate whether Coum-TAC inhibits the synthesis of mycolic acids similarly to TAC, ${ }^{14} \mathrm{C}$ acetate metabolic labeling of M.tb H37Ra treated with Coum-TAC or TAC was performed. When the cells of M.tb H37Ra reached OD $(600 \mathrm{~nm}) \sim 0.27$, CoumTAC or TAC were added in final concentrations $0.01,0.05,0.1$ and $0.25 \mu \mathrm{g} / \mathrm{ml}$. After $24 \mathrm{~h}$ of treatment, ${ }^{14} \mathrm{C}$ label was added followed by further $24 \mathrm{~h}$ cultivation. Lipids and mycolic acids isolated from the ${ }^{14} \mathrm{C}$ labeled cells were analyzed by TLC. While 
Coum-TAC did not affect the synthesis of any of major phospholipids, it completely abolished the synthesis of trehalose monomycolates (TMM) and trehalose dimycolates (TDM) in tested conditions (Figure 4A). Correlating with this observation, Coum-TAC did not inhibit the synthesis of standard fatty acids, however it completely blocked the synthesis of all forms of mycolic acids (Figure 4B). CoumTAC thereby exhibits the same inhibition effect as TAC.
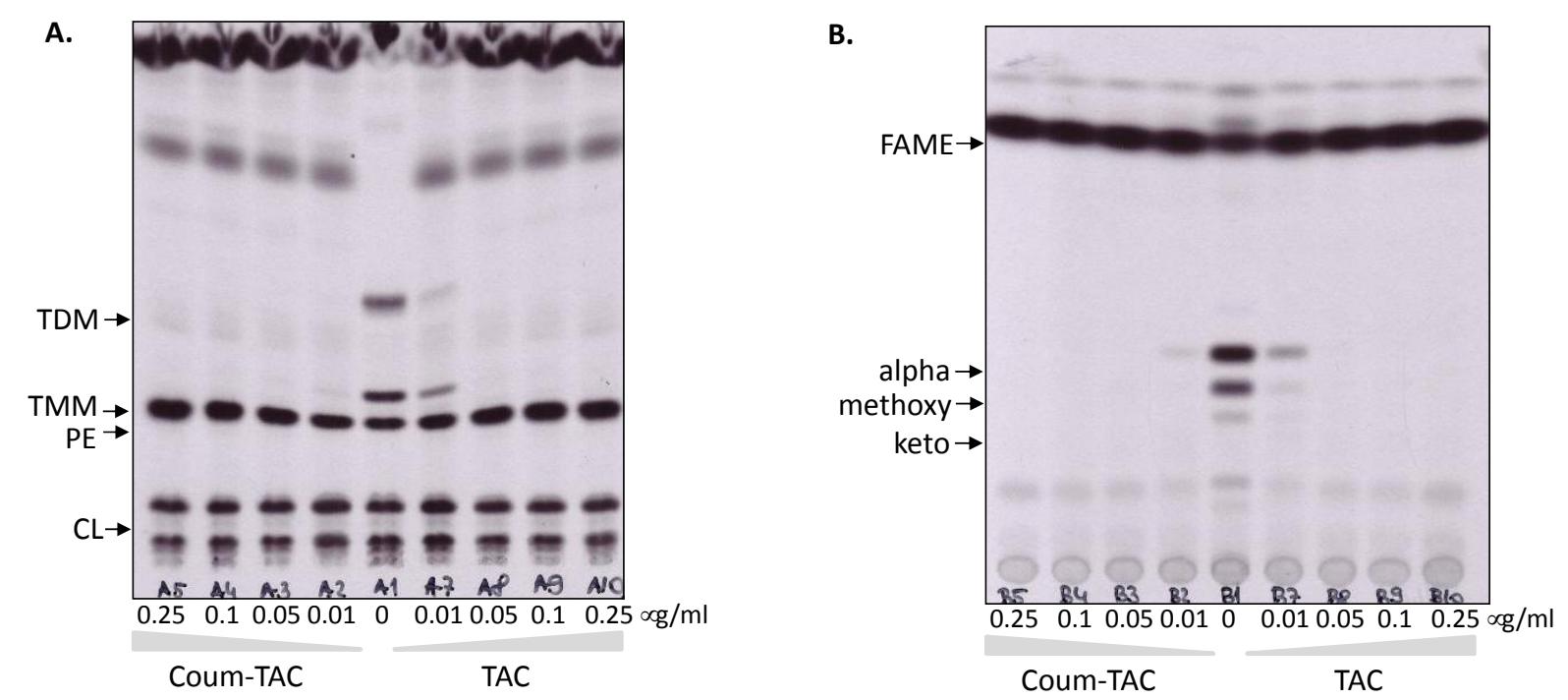

Figure 4. TLC analysis of (A) lipids and (B) methyl esters of fatty (FAME) and mycolic (MAME) acids isolated from ${ }^{14} \mathrm{C}$ labeled M.tb H37Ra cells treated with Coum-TAC or TAC. Lipids were separated in chloroform/methanol/water (20:4:0.5) and detected by autoradiography. Different forms of methyl esters were separated in $n$-hexane/ethyl acetate (95:5; 3 runs) and detected by autoradiography (with TDM: trehalose dimycolates; TMM: trehalose monomycolates; PE: phosphatidylethanolamine; CL: cardiolipin; alpha-, methoxy- and keto- refer to the forms of MAMEs).

\section{Resistance against Coum-TAC resulting from overproduction of HadABC in} M.tb. To confirm that Coum-TAC targets the dehydratase in FASIl system, the HadABC protein complex was overproduced in M.tb H37Ra using pVV16-hadABC construct $^{34}$. The analysis of MIC of Coum-TAC and TAC against i) control M.tb H37Ra strain carrying empty plasmid pVV16 and ii) against M.tb H37Ra strain overproducing HadABC revealed dramatically increased MIC values of both compounds due to overproduction of HadABC reaffirming the same mode of action of TAC and Coum-TAC in mycobacterial cells (Table 2). As expected, no difference in MIC of Coum-TAC was observed after overproduction of another protein of FAS-II complex, enoyl-acyl-ACP reductase InhA.

Table 2. Activity of Coum-TAC and TAC against different M.tb H37Ra strains 


\begin{tabular}{cccc}
\hline Entry & M.tb strains & $\begin{array}{c}\text { MIC }(\mu \mathrm{g} / \mathrm{mL}) \\
\text { Coum-TAC }\end{array}$ & $\begin{array}{c}\text { MIC }(\mu \mathrm{g} / \mathrm{mL}) \\
\text { TAC }\end{array}$ \\
\hline $\mathbf{1}$ & pVV16 & $0.01-0.02$ & 0.02 \\
$\mathbf{2}$ & pVV166-hadABC & $>50^{a}$ & $>50^{a}$ \\
$\mathbf{3}$ & pMV261 & $0.01-0.02$ & 0.02 \\
$\mathbf{4}$ & pMV261-inhA & $0.01-0.02$ & 0.02 \\
\hline
\end{tabular}

${ }^{a}$ Higher concentrations were not tested due to solubility issues.

Stimulation of in vitro HadA dimerization by TAC and Coum-TAC. In a previous work, it was shown that in mycobacterial cells, TAC covalently binds to Cys61 of HadA protein. ${ }^{10}$ We have therefore investigated, whether Coum-TAC exerts the same behavior. We performed in vitro reactions containing isolated proteins HadA and EthA, NADPH and Coum-TAC. Alternatively, the reaction mixtures contained TAC to compare the effects of both compounds. After $1 \mathrm{~h}$ incubation of the reactions at $37{ }^{\circ} \mathrm{C}$, the proteins were analyzed on SDS-PAGE in non-reducing and reducing conditions. Interestingly, the addition of both compounds, TAC, as well as CoumTAC, led to the formation of HadA dimer that depended on the presence of EthA activator (Figure 5). The addition of the reducing agent, 2-mercaptoethanol, to these samples resulted in disintegration of dimer and appearance of HadA monomer. It was suggested, that the presence of the second Cys residue (Cys105) in HadA may cause the HadA-drug adducts unstable, causing the formation of intramolecular Cys61-Cys105 disulfide bond in the protein (Scheme 1). ${ }^{11}$ We suggest that in our cell-free system containing isolated HadA protein in the presence of activated drugs, Cys61 interacts preferentially with Cys61 of another HadA molecule and thus observed homodimers are formed. 

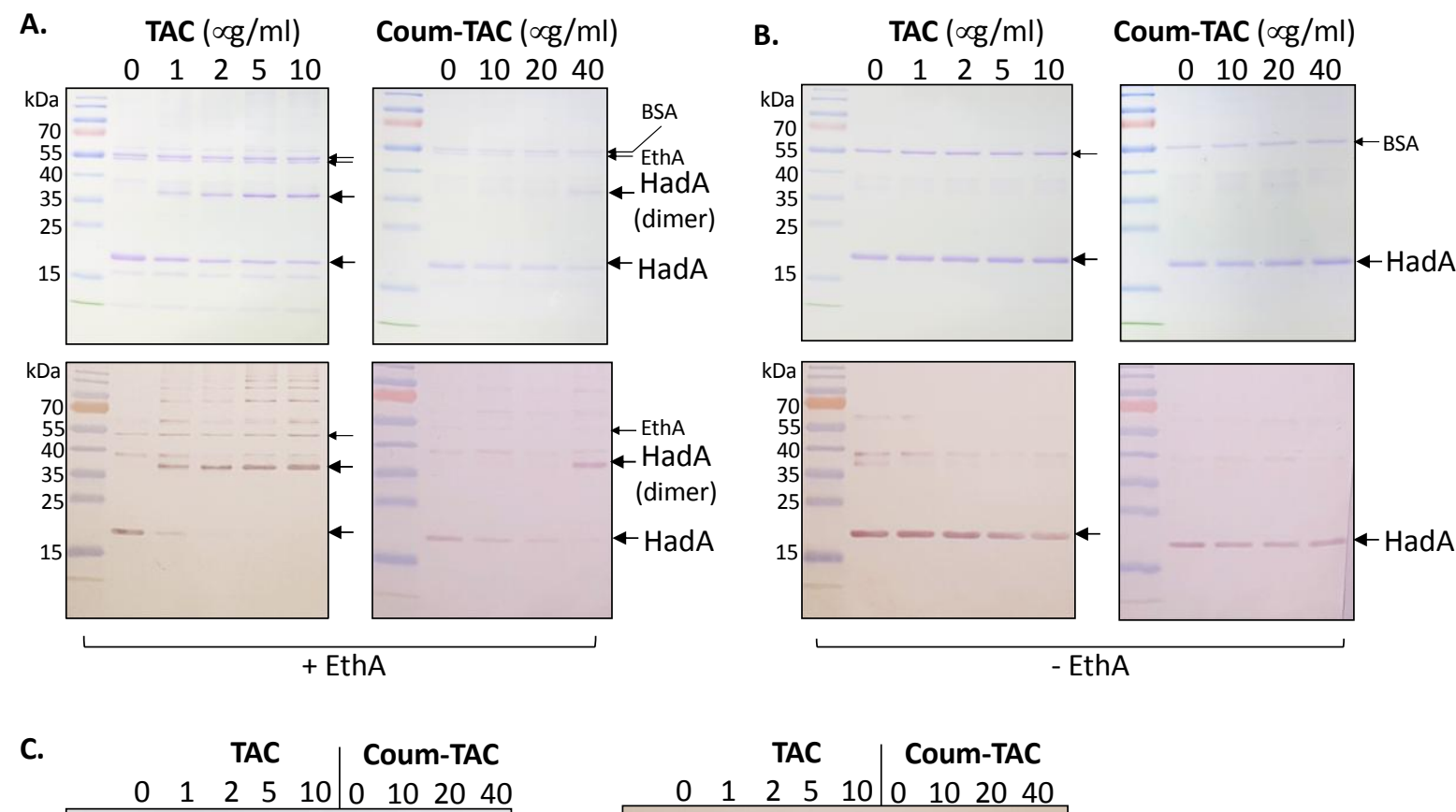

TAC $\mid$ Coum-TAC

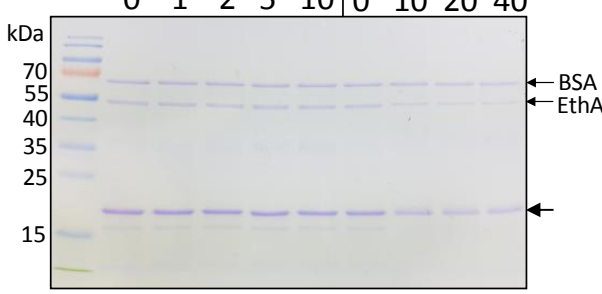

\begin{tabular}{lllll|llll}
0 & 1 & 2 & 5 & 10 & 0 & 10 & 20 & 40
\end{tabular}

+ EthA + 2-Mercaptoethanol

Figure 5. Formation of HadA dimer under cell-free conditions. SDS-PAGE analysis of proteins from reaction mixtures containing: (A) isolated proteins HadA and EthA, as well as TAC or Coum-TAC. The samples were analyzed in non-reducing environment. Up: gel stained with Coomassie Brilliant Blue; Down: immunodetection using anti-His antibodies; (B) only isolated protein HadA and TAC or CoumTAC. The samples were analyzed in non-reducing environment. Up: gel stained with Coomassie Brilliant Blue; Down: immunodetection using anti-His antibodies; (C) isolated proteins HadA and EthA, as well as TAC or Coum-TAC. The samples were analyzed in the presence of 2-mercaptoethanol. Left: gel stained with Coomassie Brilliant Blue / Right: immunodetection using anti-His antibodies.

Covalent binding of EthA-activated Coum-TAC to HadA. To demonstrate that once activated Coum-TAC might act on $\operatorname{HadA}$, the EthA activation reaction was performed in the presence of HadA protein. The blank control was performed omitting $\mathrm{NADPH}$ to hinder the EthA-catalyzed reaction. After $1 \mathrm{~h}$ incubation of the reaction at $37^{\circ} \mathrm{C}$, HadA was re-purified by Ni-NTA chromatography, to remove EthA as well as any unbound compound, and dialyzed. Finally, the UV-visible spectra of the HadA samples were analyzed. As depicted in Figure 6A, the UV-Vis spectrum of HadA incubated with EthA reaction shows an additional peak at $470 \mathrm{~nm}$, which is characteristic of the Coum-TAC compound. This peak being also present in the blank reaction, it is conceivable that Coum-TAC can bind HadA with low affinity, 
which is greatly increased upon EthA activation that mediates the formation of interaction. Thus, to ascertain if a covalent bound is formed between HadA and the activated Coum-TAC, the protein was subjected to heat denaturation. The denaturated protein was centrifuged, the pellet was resuspended in $10 \%$ sodium dodecylsulfate solution and for both pellet and supernatant, UV-Vis spectra were recorded. As shown in Figure 6B, the peak at $470 \mathrm{~nm}$ of Coum-TAC was present in the spectrum of the denaturated HadA, only if the protein had been incubated with the complete reaction. Moreover, the labeled protein showed a fluorescence spectrum similar to that of the Coum-TAC (Figure 6C); once again, the protein after thermal denaturation showed fluorescence only after incubation with Coum-TAC, EthA and NADPH (Figure 6D).

The fluorescence properties of Coum-TAC are not altered by the EthA activation or by the formation of the complex with HadA, as shown by the fact that the spectra of the reaction mixture did not change during the incubation (Figure S3 in the Supporting Information). Finally, to further confirm that Coum-TAC covalently bind HadA, the enzyme treated with EthA and the compound as above, was dialyzed and subjected for mass analysis. As shown in (Figure S4 in the Supporting Information), HadA protein incubated with DMSO showed a MW of $18060 \mathrm{Da}$. By contrast, the protein showed a MW of $18440 \mathrm{Da}$ after incubation with Coum-TAC, with a mass increase of $380 \pm 40$ Da thus compatible with the formation of a covalent adduct.

Taken together, these data clearly demonstrate that EthA promotes the formation of a covalent adduct between Coum-TAC and HadA. 
(A)

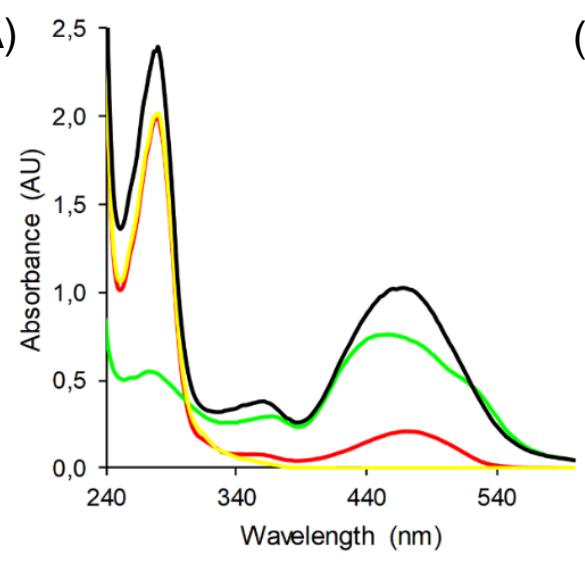

(C)

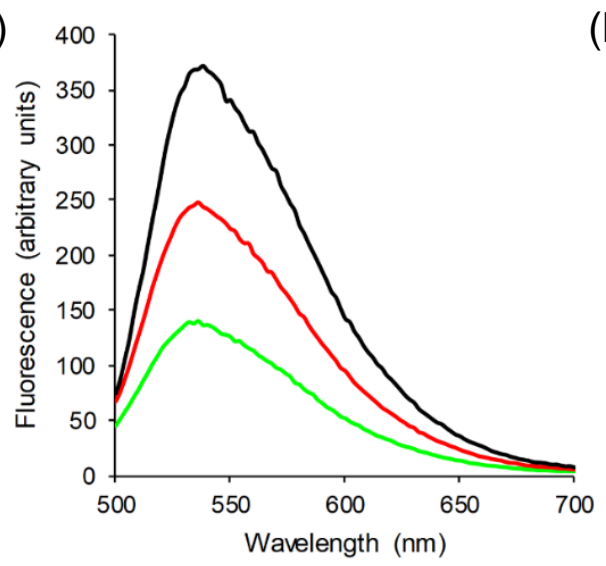

(B)

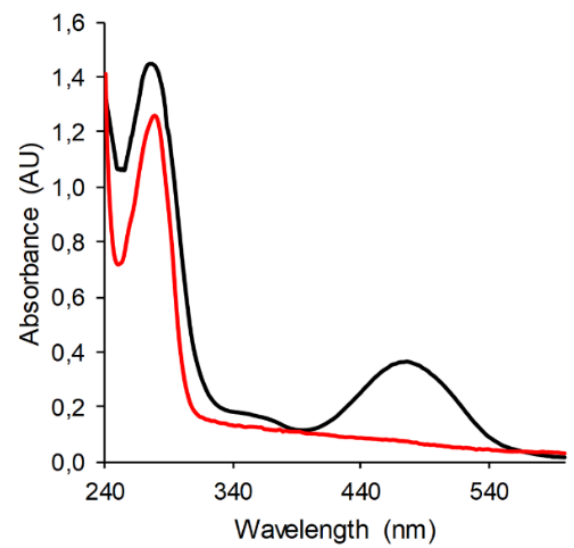

(D)

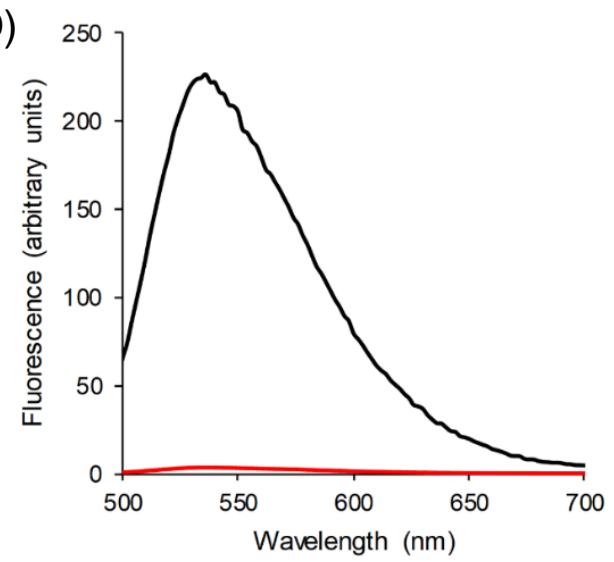

Figure 6. Covalent binding of EthA-activated Coum-TAC to HadA. (A) UV-vis spectrum of HadA protein, re-purified after the reaction with EthA and Coum-TAC (black line), compared with the blank reaction (red line). Green line represents the spectrum of Coum-TAC, while yellow line is the spectrum of HadA before incubation. (B) UV-vis spectrum of HadA/Coum-TAC adduct after heat denaturation (black line), compared with the blank reaction (red line). (C) Emission spectra (excitation at $470 \mathrm{~nm}$ ) of HadA/Coum-TAC adduct at $0.5 \mathrm{mg} / \mathrm{mL}$ (green line), $1 \mathrm{mg} / \mathrm{mL}$ (red line) and $2 \mathrm{mg} / \mathrm{mL}$ (black line). (D) Emission spectra (excitation at $470 \mathrm{~nm}$ ) of HadA/Coum-TAC adduct after heat denaturation (black line), compared with the blank reaction (red line).

Fluorescent labeling of M.tb mycobacteria in the presence of Coum-TAC. With the previous results in hand, we further investigated the ability of Coum-TAC to image M.tb cells growths using fluorescence microscopy with the idea to label HadA and to get insights on its localization in the mycobacteria. From previous studies, FAS-II enzymes were shown to colocalize at the poles and septa of the mycobacterial cells. ${ }^{12}$ With this in mind, we decided to monitor the location of fluorescence over time in a M.tb H37Rv strain in the presence of Coum-TAC at 0.5 $\mu \mathrm{g} / \mathrm{mL}$. Time-lapse fluorescence microscopy analyses of Coum-TAC incorporation in mycobacteria show a preferential accumulation at the poles and septa of the mycobacteria (Figures 7A-B). ${ }^{35}$ Interestingly Coum-TAC accumulation can be observed as soon as 2 hours after incubation with manifest peaks after 18 hours. To 
go further and explore whether the so-observed pattern of Coum-TAC incorporation can be monitored at the population level, we compared the accumulation of CoumTAC in M.tb at 18 hours after incubation with the accumulation of two model compounds i) coumarin 466, ie. the fluorescent moiety of Coum-TAC and ii) compound C2, ie. the hydrolyzed form of Coum-TAC (Figure 7E). To do this, we employed Lattice-Structured Illumination Microscopy (SIM), ${ }^{36}$ a super-resolution microscopy technique in order to get a more resolved localization of these fluorescent compounds in M.tb (Figures 7C-D). The obtained images first revealed that coumarin 466 is poorly incorporated in M.tb in sharp contrast to C2 and Coum-TAC compounds. Moreover, the patterns of incorporation of Coum-TAC and C2 are significantly different, despite the observed heterogeneity which is expected ${ }^{37,38}$. While Coum-TAC proved to accumulate preferentially in both poles of M.tb in the form of foci, the accumulation of $\mathbf{C 2}$ in M.tb is homogeneous, with a slightly increased accumulation in one of the poles, without forming foci. Also of significance is that the noticeable difference of incorporation patterns of Coum-TAC vs C2 further revealed the stability of Coum-TAC under the applied biological conditions. 
(A)

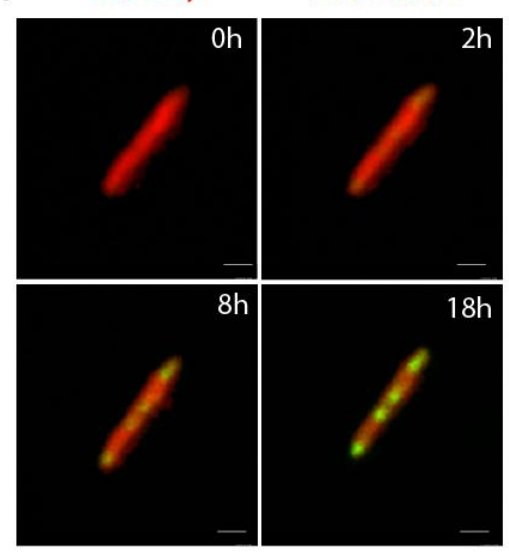

(C)

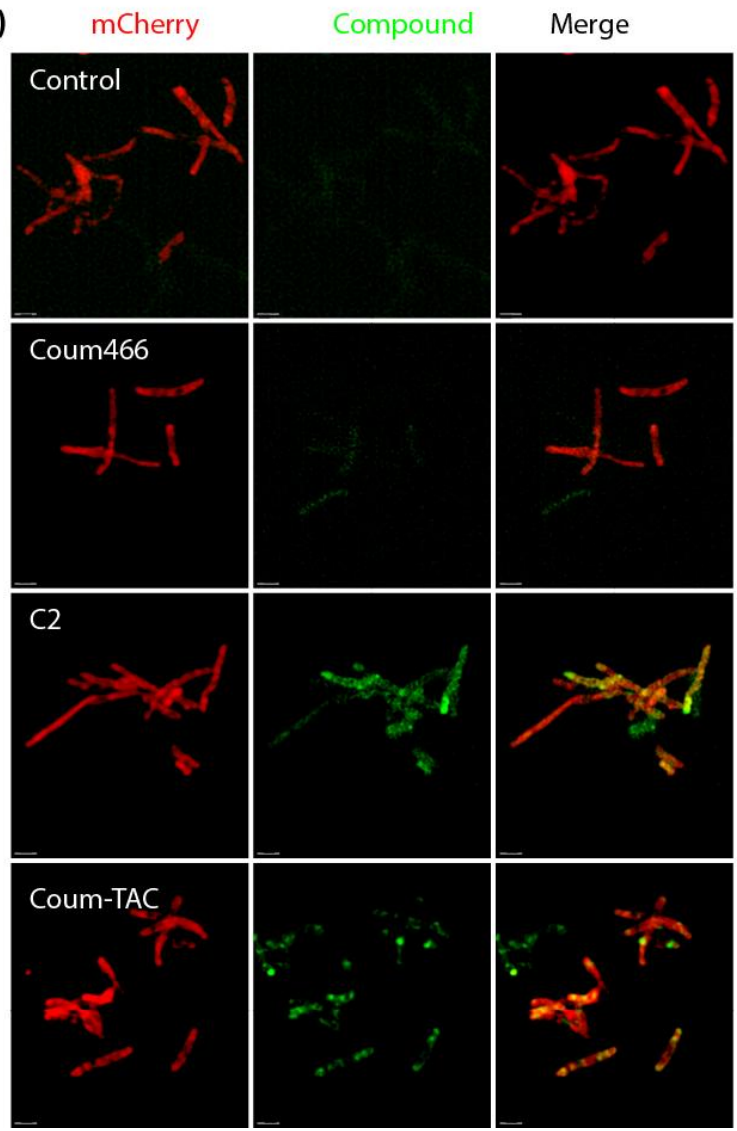

(B)

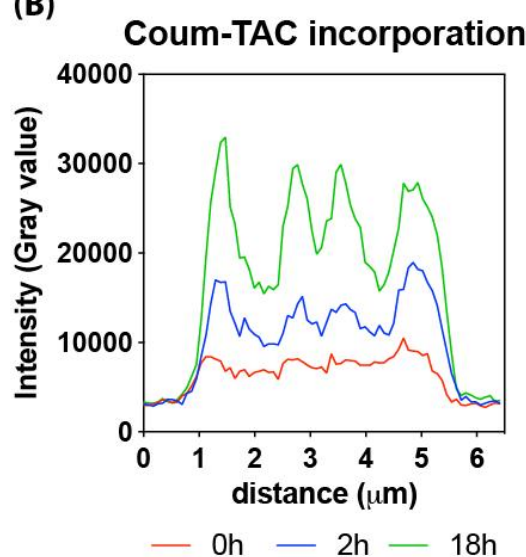

(D) Incorporation Profile

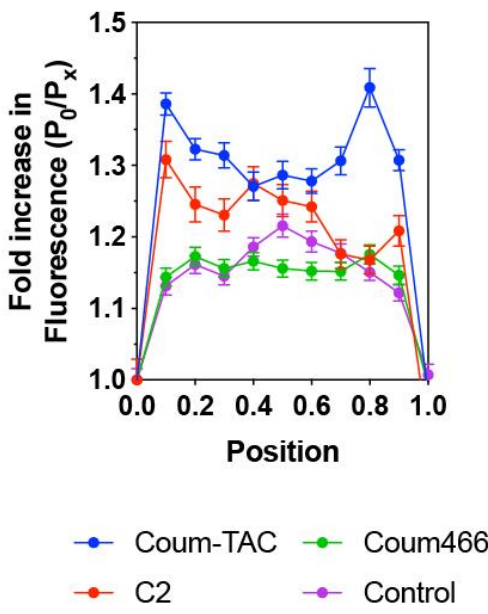

(E) Chemical structures

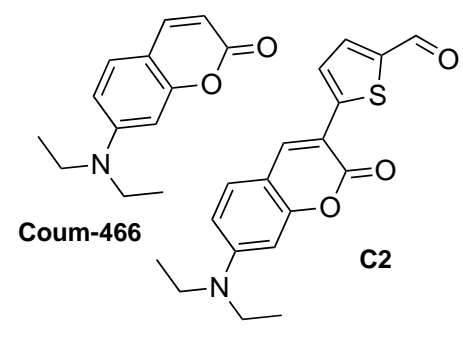

Figure 7. Imaging of M.tb H37Rv strain incubated with Coum-TAC. (A) Monitoring of fluorescence in M.tb H37Rv mycobacteria expressing m-Cherry (red) with time-dependent fluorescence increase of Coum-TAC (in green) at the poles and septa. (B) Time-dependent Coum-TAC distribution along the medial axis of the mycobacteria. (C) Lattice-SIM microscopy of coumarin 466, C2 and Coum-TAC (in green) in M.tb H37Rv mycobacteria expressing m-Cherry (red). (D) M.tb was segmented using mCherry fluorescence and intensity profiles of fluorescence of each compound was measured along the medial axis of each bacilli using the MicrobeJ plugin of ImageJ. Results show variation of intensity along the medial axis from the first pole $\left(P_{0}\right)$ to the opposing pole at regular intervals $\left(P_{x}\right)$. Mean \pm SEM of $>100$ individual bacteria per condition. (E) Chemical structures of coumarin-466 and $\mathbf{C 2}$.

Altogether, our results proving the mechanism of action of Coum-TAC together with the localization studies in M.tb strongly indicate that it selectively accumulates at the 
poles, thus suggesting the polar localization of HadA enzyme similar as other FAS-II enzymes.

\section{CONCLUSION}

We reported herein the rational design and straightforward synthesis of Coum-TAC, a covalent conjugate of a thiacetazone-derived anti-TB agent with a fluorescent coumarin-based moiety enabling the dual covalent inhibition and fluorescent labeling of HadA. First, Coum-TAC proved to exhibit an excellent anti-TB efficiency with a profile similar to that of well-known thiacetazone derivatives. The similarity of mode of action was further confirmed by the effective activation of Coum-TAC by EthA and by its reaction with HadA to furnish a fluorescent HadA/Coum-TAC adduct. Finally, the easy-to-prepare molecule Coum-TAC was successfully implemented as an imaging probe capable of labeling Mycobacterium tuberculosis with a manifest selectivity for the poles of the bacteria, thus suggesting a polar localization of HadA in M.tb.

\section{EXPERIMENTAL SECTION}

\section{Chemistry - synthesis of Coum-TAC (Scheme 2)}

General - Starting materials were purchased at the highest commercial quality and used without further purification unless otherwise stated. Cyclohexane, acetic acid, ethanol $(\mathrm{EtOH})$, dichloromethane, $(N, M)$-dimethylformamide (DMF), diethyl ether and ethyl acetate (EtOAc) and were purchased and used as received. - Reactions were monitored by thinlayer chromatography carried out on silica plates (silica gel $60 \mathrm{~F}_{254}$, Merck) using UV-light for visualization. - Evaporation of solvents were conducted under reduced pressure at temperatures less than $30^{\circ} \mathrm{C}$. - Melting points (M.p.) were measured in open capillary tubes on a Stuart SMP30 apparatus and are uncorrected. - IR spectra were obtained from the 'Service Commun de Spectroscopie Infrarouge' of the Plateforme Scientifique et Technique, Institut de Chimie de Toulouse (FR2599), and values are reported in $\mathrm{cm}^{-1} .-{ }^{1} \mathrm{H}$ and ${ }^{13} \mathrm{C} \mathrm{NMR}$ spectra were recorded on a Bruker Avance 300 spectrometer at 300 and $75 \mathrm{MHz}$, respectively. Chemical shifts $(\delta)$ and coupling constants $(\mathcal{J}$ are given in ppm and Hertz $(\mathrm{Hz})$, respectively. The signal multiplicity is described according to the following abbreviations: $s$ (singlet), bs (broad singlet), d (doublet), and $t$ (triplet). Chemical shifts $(\delta)$ are reported relative to the residual solvent as an internal standard (DMSO-d $\mathrm{d}_{6}: \delta=2.50 \mathrm{ppm}$ for ${ }^{1} \mathrm{H}$ and $\delta$ $=39.5 \mathrm{ppm}$ for $\left.{ }^{13} \mathrm{C}\right)$. - Electrospray $(\mathrm{ESI})$ low/high-resolution mass spectra were obtained from the 'Service Commun de Spectroscopie de Masse' of the Plateforme Technique, Institut de Chimie de Toulouse (FR2599). Accurate mass measurements (HRMS) were performed with a Q-TOF analyzer. - Crystallographic data for compound $3^{39,40}$ were collected on a Bruker-AXS Quazar APEX II diffractometer using a $30 \mathrm{~W}$ air-cooled microfocus source (ImS) with focusing multilayer optics at a temperature of $193(2) \mathrm{K}$, with $\mathrm{MoK}_{\alpha}$ radiation (wavelength - $0.71073 \AA$ A ) using phi- and omega-scans. Semi-empirical absorption correction was employed. ${ }^{41}$ The structure was solved using an intrinsic phasing method (SHELXT), ${ }^{42}$ and 
refined using the least-squares method on $F^{2}{ }^{37}$ All non- $\mathrm{H}$ atoms were refined with anisotropic displacement parameters. Hydrogen atoms were refined isotropically at calculated positions using a riding model with their isotropic displacement parameters constrained to be equal to 1.5 times the equivalent isotropic displacement parameters of their pivot atoms for terminal $\mathrm{sp}^{3}$ carbon and 1.2 times for all other carbon atoms.

Synthesis of precursor 3 (5-(7-(( $N, N)$-diethylamino)-2-oxo-2H-chromen-3-yl)thiophene2-carbaldehyde) - Step 1 - In a $250 \mathrm{~mL}$ three-neck flask equipped with a Dean-Stark apparatus were successively added 4 - $(N, N)$-diethylaminosalicylaldehyde (15.0 mmol), 2thiopheneacetonitrile $(15.0 \mathrm{mmol})$, cyclohexane $(25 \mathrm{~mL})$ and activated IRA-900 resin $(5 \mathrm{~g})$ as strong basic catalyst. The resulting mixture was then heated at reflux under nitrogen and after $8 \mathrm{~h}$ stirring, the reaction was complete as revealed by TLC analysis. After cooling to room temperature, the solid materials were removed by filtration and further washed with dichloromethane. The resulting organic phase was then evaporated to give the iminocoumarin intermediate $\mathbf{1}$ as a solid which was used in the second step without any further purification. - Step 2 - A mixture of acetic acid $(20 \mathrm{~mL})$ and $\mathrm{EtOH}(10 \mathrm{~mL})$ was next added to the crude 1. After $4 \mathrm{~h}$ stirring at $80^{\circ} \mathrm{C}$, the reaction mixture was cooled to room temperature and the resulting solid was recovered by filtration, washed with cold $\mathrm{EtOH}$ and dried under vacuum to give the expected coumarin intermediate 2, again used in the next step without any further purification. - Step 3 - After dropwise addition of DMF $(10 \mathrm{~mL})$ to phosphorus oxytrichloride $(3 \mathrm{~mL})$ at $40^{\circ} \mathrm{C}$, the resulting mixture was further stirred at $50{ }^{\circ} \mathrm{C}$ for $45 \mathrm{~min}$. After cooling to room temperature, a suspension of crude 2 in DMF ( $3 \mathrm{~mL})$ was added and the reaction mixture was heated to $60^{\circ} \mathrm{C}$. After $4 \mathrm{~h}$ stirring at this temperature, the reaction was complete as revealed by TLC analysis and the reaction mixture was then poured into ice $(100 \mathrm{~g})$. After stirring for two additional hours, the solid materials were recovered by filtration, washed with water and dried in an oven at $50{ }^{\circ} \mathrm{C}$, to furnish the expected formylated coumarin 3 as orange crystals at $>95 \%$ purity as judged by ${ }^{1} \mathrm{H}$ NMR. Yield $78 \%$. - This formylated coumarin precursor 3 is a known compound and exhibit spectroscopic data identical to the previously ones in the literature. ${ }^{43,44}$

Synthesis of Coum-TAC ((E)-((5-(7-((N,N)-diethylamino)-2-0x0-2H-chromen-3yl)thiophen-2-yl)methylene)hydrazine-1-carbothioamide) - In a ChemSpeed Accelerator SLT-106 synthesizer reactor equipped with a refrigerant system were successively added coumarin $3(0.3 \mathrm{mmol})$, thiosemicarbazide $(0.3 \mathrm{mmol})$, EtOH $(15 \mathrm{~mL})$ as solvent, and $1 \mathrm{M}$ aqueous $\mathrm{HCl}(15 \mu \mathrm{L})$. After $5 \mathrm{~h}$ orbital shaking at $600 \mathrm{rpm}$ and $90^{\circ} \mathrm{C}$, the resulting precipitate was recovered by filtration, washed with diethyl ether and $\mathrm{EtOH}$ and dried under vacuum to furnish Coum-TAC in pure forms as an orange solid. - Yield $89 \%$. M.p. $260{ }^{\circ} \mathrm{C}$. $-R_{f}=0.50$ (4:6 cyclohexane/EtOAc). - FTIR-ATR (neat) 3345, 3250, 3165, 1680, 1610, 1575, $1510 \mathrm{~cm}^{-}$ 1. - ${ }^{1} \mathrm{H}$ NMR $\left(300 \mathrm{MHz}, \mathrm{DMSO}-\mathrm{d}_{6}\right): \delta=11.44(\mathrm{~s}, 1 \mathrm{H}), 8.46(\mathrm{~s}, 1 \mathrm{H}), 8.21(\mathrm{~d}, \mathrm{~J}=0.9 \mathrm{~Hz}, 1 \mathrm{H})$, 8.19 (bs, $1 \mathrm{H}), 7.66(\mathrm{~d}, \mathrm{~J}=4.0 \mathrm{~Hz}, 1 \mathrm{H}), 7.54$ (bs, $1 \mathrm{H}), 7.52(\mathrm{~d}, \mathrm{~J}=9.0 \mathrm{~Hz}, 1 \mathrm{H}), 7.43(\mathrm{~d}, \mathrm{~J}=4.1$ $\mathrm{Hz}, 1 \mathrm{H}), 6.78(\mathrm{dd}, \mathrm{J}=8.9,2.4 \mathrm{~Hz}, 1 \mathrm{H}), 6.60(\mathrm{~d}, \mathrm{~J}=2.4 \mathrm{~Hz}, 1 \mathrm{H}), 3.46(\mathrm{q}, \mathrm{J}=7.0 \mathrm{~Hz}, 4 \mathrm{H}), 1.14$ (t, J = 6.9 Hz, 6H). ${ }^{13} \mathrm{C}$ NMR (75 MHz, DMSO): $\delta=177.4,159.6,155.4,150.8,139.3$, 138.1, 138.0, 137.9, 130.6, 129.8, 124.4, 112.3, 109.8, 108.1, 96.2, 44.2, 12.4. - LRMS (ESI, positive mode): $m / z$ (rel intensity) $401\left([\mathrm{MH}]^{+}, 100\right)$.

\section{Biology -}


MIC determination in vitro - M.tb strain H37Rv, used as the reference strain, and all the M.tb mutants were grown at $37{ }^{\circ} \mathrm{C}$ in Middlebrook $7 \mathrm{H} 9$ broth (Difco), supplemented with $0.05 \%$ Tween80, or on solid Middlebrook $7 \mathrm{H} 11$ medium (Difco) supplemented with oleic acid-albumin-dextrose-catalase (OADC). MICs for the compounds were determined by means of the micro-broth dilution method. Dilutions of M.tb wild-type or mutant strains (about $10^{5}-10^{6} \mathrm{cfu} / \mathrm{mL}$ ) were streaked onto $7 \mathrm{H} 11$ solid medium containing a range of drug concentrations. Plates were incubated at $37^{\circ} \mathrm{C}$ for about 21 days and the growth was visually evaluated. The lowest drug dilution at which visible growth failed to occur was taken as the MIC value. Results were expressed as the average of at least three independent determinations. M.tb H37Ra strains carrying empty vectors pMV261 or pVV16 and M.tb H37Ra InhA41 or HadABC33 overproducing strains were grown in Middlebrook 7H9 broth (Difco) supplemented with albumin-dextrose-catalase and $0.05 \%$ Tween 80 in 96-well plates in the presence of $0,0.001,0.005,0.01,0.02,0.05,0.25,0.5,1,5,25$ and $50 \mu \mathrm{g} / \mathrm{mL}$ of Coum-TAC or TAC. Plates were incubated at $37^{\circ} \mathrm{C}$ for 12 days and the growth was evaluated by measuring the values at OD $(600 \mathrm{~nm})$.

Time-killing assay - M.tb H37Rv was cultured in 7H9 broth to mid-log phase. Bacteria were diluted to about $10^{5} \mathrm{CFU} / \mathrm{ml}$ to inoculate $10-\mathrm{mL}$ cultures growing in $50 \mathrm{ml}$ Falcon tubes. TAC and Coum-TAC were added at MIC concentration $(0.5$ and $1 \mu \mathrm{g} / \mathrm{ml}$, respectively) and 10fold. At indicated time points, samples were collected, 10 -fold serially diluted samples were plated on Middlebrook 7H11 agar plates supplemented with 10\% OADC. After three weeks, viable counts were determined. Isoniazid was used as control at 0.5 -fold MIC concentration.

${ }^{14} \mathrm{C}$ metabolic labeling of $M$. tb H37Ra and analysis of lipids and mycolic acids - The M.tb H37Ra strain was grown by shaking at $37^{\circ} \mathrm{C}$ in Middlebrook $7 \mathrm{H} 9$ broth (Difco) supplemented with albumin-dextrose-catalase and $0.05 \%$ Tween 80 . At OD $(600 \mathrm{~nm})$ of 0.27 , the culture was divided into $200 \mu \mathrm{L}$ aliquots and a DMSO solution of the tested compound was added in $0,0.01,0.05,0.1$ and $0.25 \mu \mathrm{g} / \mathrm{mL}$ final concentrations. The final concentration of DMSO in each culture was kept $2 \%$. The cells grew $24 \mathrm{~h}$ at $37^{\circ} \mathrm{C}$ shaking at $120 \mathrm{rpm}$. Then $\left[1,2-{ }^{14} \mathrm{C}\right]$-acetate (specific activity $110 \mathrm{mCi} / \mathrm{mmol}, \mathrm{ARC}$ ) was added in the final concentration $0.5 \mu \mathrm{Ci} / \mathrm{mL}$ and the cultures continued growing for next $24 \mathrm{~h}$. The cells were harvested and the lipids were extracted with $3 \mathrm{~mL}$ chloroform/methanol (1:2) at $56{ }^{\circ} \mathrm{C}$ for $2 \mathrm{~h}$ followed by two extractions with $3 \mathrm{~mL}$ chloroform/methanol (2:1) at the same conditions. The organic extracts were combined together in the clean tube, dried under $\mathrm{N}_{2}$ and washed by Folch. ${ }^{45}$ Isolated lipids were dissolved in $50 \mu \mathrm{L}$ of chloroform: methanol (2:1) and $5 \mu \mathrm{L}$ were loaded on the thin-layer chromatography (TLC) silica gel plates F254 (Merck). Lipids were separated in chloroform/methanol/water (20:4:0.5) and the plates were exposed to autoradiography film Biomax MR (Kodak) at $-80{ }^{\circ} \mathrm{C}$ for 5 days. Methyl esters of fatty acids (FAME) and mycolic acids (MAME) were prepared as previously described. ${ }^{46}$ Dried extracts were dissolved as described for lipids and $5 \mu \mathrm{L}$ were loaded on TLC plates and different forms of methyl esters were separated in $n$-hexane/ethyl acetate (95:5), 3 runs and detected by autoradiography. The plates were exposed to autoradiography film Biomax MR (Kodak) at $-80^{\circ} \mathrm{C}$ for 5 days.

Production of M.tb EthA and activation of Coum-TAC - EthA from M.tb was expressed and purified to homogeneity, according to the previously published method. ${ }^{31}$ Enzyme activity assays were performed by a spectrophotometric method, following the decrease in 
absorbance of NADPH at $340 \mathrm{~nm}\left(\varepsilon=6.22 \mathrm{mM}^{-1} \mathrm{~cm}^{-1}\right) \cdot{ }^{31}$ Assays were performed at $37^{\circ} \mathrm{C}$, in an Eppendorf BioSpectrometer. Reaction mixtures typically contained $50 \mathrm{mM}$ potassium phosphate $\mathrm{pH}$ 8.0, $0.2 \mathrm{mM} \mathrm{NADPH}, 10 \mu \mathrm{M}$ bovine serum albumin (BSA), $50 \mu \mathrm{M}$ of CoumTAC, and the reaction was started by adding the enzyme solution $(1 \mu \mathrm{M})$.

Steady-state kinetics parameters were determined by assaying the enzymes at least at 8 different concentrations of compound. All experiments were performed in triplicate, and the kinetic constants, $K_{\mathrm{m}}$ and $k_{\mathrm{cat}}$, were determined fitting the data to the Michaelis-Menten equation using Origin 8 software.

In order to obtain the HadA protein complexed with the EthA activated Coum-TAC, the enzyme was incubated with the compound in the presence of the monooxygenase. Briefly, HadA $(50 \mu \mathrm{M})$ was incubated with EthA $(10 \mu \mathrm{M})$ in $50 \mathrm{mM}$ potassium phosphate buffer $\mathrm{pH}$ 8.0, $200 \mu \mathrm{M}$ NADPH, $10 \mu \mathrm{M}$ Bovine Serum Albumin, $100 \mu \mathrm{M}$ Coum-TAC, at $37^{\circ} \mathrm{C}$. For the blank control, NADPH was omitted from the reaction mixture, in order to avoid prodrug activation.

The reaction was followed by monitoring the decrease in absorbance at $340 \mathrm{~nm}$ of NADPH, and after $1 \mathrm{~h}$ of incubation, the reaction mixture was loaded on a Ni-NTA column equilibrated in $50 \mathrm{mM}$ potassium phosphate $\mathrm{pH} 7.5,50 \mathrm{mM} \mathrm{KCl}$. The column was washed with the same buffer to elute EthA, unbound Coum-TAC and metabolite(s), then HadA was eluted with 500 $\mathrm{mM}$ imidazole in the same buffer, dialyzed against $50 \mathrm{mM}$ potassium phosphate $\mathrm{pH}$ 8.0, and concentrated. The formation of the HadA-Coum-TAC was assessed by monitoring the UVvis and fluorescence spectra. Fluorescence measurements were performed on a Cary Eclipse Fluorescence Spectrophotometer (Varian). The excitation wavelength was $470 \mathrm{~nm}$ (3 $\mathrm{nm}$ slit width) and the emission was recorded between 500 and $680 \mathrm{~nm}$ (10 nm slit width). To confirm the covalent nature of the interaction between $\mathrm{HadA}$ and the activated Coum-TAC, the protein and the compound were incubated with EthA, then HadA purified as above. The protein was then incubated at $100{ }^{\circ} \mathrm{C}$ for 10 minutes. The denaturated protein was centrifuged $15 \mathrm{~min}$ at $12000 \mathrm{rpm}$, resuspended in a $10 \%$ aqueous sodium dodecylsulfate (SDS) solution, and UV-vis and fluorescence spectra were again recorded and compared to that of the control reaction, performed as above.

For MS analysis, the samples prepared as above were dialyzed, concentrated to $20 \mu \mathrm{l}$, diluted $1: 5$ in methanol-water $1: 1$ containing $0.01 \%$ formic acid, and directly analyzed in mass spectrometry, using an lon Trap (LCQ FleetTM) mass spectrometer with electrospray ionization (ESI) ion source controlled by Xcalibur software 2.2. Mass spectra, recorded for two minutes, were generated in positive ion mode under constant instrumental conditions: source voltage $5.0 \mathrm{kV}$, capillary voltage $46 \mathrm{~V}$, sheath gas flow 20 (arbitrary units), auxiliary gas flow 10 (arbitrary units), sweep gas flow 1 (arbitrary units), capillary temperature $210^{\circ} \mathrm{C}$, tube lens voltage $105 \mathrm{~V}$. MS/MS spectra, obtained by CID studies in the ion trap, were performed with an isolation width of $3 \mathrm{Da} \mathrm{m} / \mathrm{z}$, the activation amplitude was $35 \%$ of ejection $\mathrm{RF}$ amplitude that corresponds to $1.58 \mathrm{~V}$. Spectra deconvolution was performed using UniDec 3.2.0 software.

In vitro monitoring the effect of TAC and Coum-TAC on HadA protein - Recombinant HadA protein carrying C-terminal Has $_{6}$-tag was produced in M. smegmatis $\mathrm{mc}^{2} 155$ strain using pVV16-hadA construct. ${ }^{10}$ The cells were grown in LB medium containing $20 \mu \mathrm{g} / \mathrm{mL}$ kanamycin at $37{ }^{\circ} \mathrm{C}$, shaking $(130 \mathrm{rpm})$ and harvested in the exponential phase of growth. The cells were resuspended in equal volume of isolation buffer $(50 \mathrm{mM} \mathrm{TrisHCl} \mathrm{pH}=7.5$; 
$150 \mathrm{mM} \mathrm{NaCl} ; 5 \mathrm{mM}$ Imidazole; $10 \mu \mathrm{g} / \mathrm{mL}$ DNase; Roche EDTA-free Protease Inhibitor) and disrupted by sonication (20 cycles, 60 s on, 90 s off). Cell lysate was centrifuged at $10000 \mathrm{x}$ $\mathrm{g}, 15 \mathrm{~min}, 4^{\circ} \mathrm{C}$ and the protein $\mathrm{HadA}$ was isolated from resulting supernatant using cobaltbased affinity chromatography with HiTrap TALON crude $1 \mathrm{~mL}$ column connected to ÄKTA start chromatography system. The protein was eluted with gradually increasing concentration of imidazole, up to $500 \mathrm{mM}$. Selected fractions containing isolated protein HadA were collected, desalted and concentrated using Amicon Ultra-15 centrifugal filter unit (10 kDa cut off).

Recombinant EthA protein carrying $\mathrm{C}$-terminal $\mathrm{Has}_{6}$-tag was produced in $M$. smegmatis $\mathrm{mc}^{2} 155$ strain using pJAM2-ethA construct. The construct was prepared by cloning of PCRamplified ethA from $M$. tuberculosis $\mathrm{H} 37 \mathrm{Rv}$ into pJAM2 vector harboring a kanamycin resistance cassette ${ }^{47}$ using ScAl and Xbal restriction sites. M. smegmatis $\mathrm{mc}^{2} 155$ pJAM2ethA was cultivated in $\mathrm{M} 63$ medium at $37{ }^{\circ} \mathrm{C}$ until $\mathrm{OD}=0.6$ at $600 \mathrm{~nm}$. At that point recombinant protein production was induced by adding $0.2 \%$ acetamide and the cells were further cultivated for $24 \mathrm{~h}$ at $30^{\circ} \mathrm{C}$. The cells were resuspended in equal volume of isolation buffer $(25 \mathrm{mM}$ TrisHCl $\mathrm{pH}=7.5 ; 300 \mathrm{mM} \mathrm{NaCl}$ ) and disrupted by sonication (20 cycles, $60 \mathrm{~s}$ on, $90 \mathrm{~s}$ off). Cell lysate was centrifuged at $10000 \times \mathrm{g}, 15 \mathrm{~min}, 4^{\circ} \mathrm{C}$ and the protein $\mathrm{EthA}$ was isolated from resulting supernatant as described above for HadA protein.

In vitro assay was performed to monitor the effect of TAC and Coum-TAC on HadA protein. Reaction mixtures contained $10 \mu \mathrm{g}$ of HadA protein, $10 \mu \mathrm{g}$ of Eth $_{\mathrm{tb}}$ protein, $4 \mathrm{mM} \mathrm{NADPH}$, $100 \mathrm{mM} \mathrm{KCl}, 100 \mu \mathrm{g} / \mathrm{mL}$ BSA and $0,1,2,5$ and $10 \mu \mathrm{g} / \mathrm{mL}$ TAC or $0,10,20$ and $40 \mu \mathrm{g} / \mathrm{mL}$ Coum-TAC (dissolved in DMSO, $2 \%$ final concentration in the reaction mixtures) and 50 $\mathrm{mM}$ Tris HCl $(\mathrm{pH}=7.5)$ in $50 \mu \mathrm{L}$ final volume. Reaction mixtures were incubated $1 \mathrm{~h}$ at $37^{\circ} \mathrm{C}$ and $10 \mu \mathrm{l}$ were mixed with non-reducing $2 \times$ sample buffer (without $\beta$-mercaptoethanol) and loaded on SDS PAGE. Alternatively, $10 \mu \mathrm{L}$ were mixed with reducing $2 \times$ sample buffer containing $\beta$-mercaptoethanol in $2 \%$ final concentration, incubated $10 \mathrm{~min}$ at $95{ }^{\circ} \mathrm{C}$ and analyzed by SDS-PAGE. Gels were stained with Coomasie Brilliant Blue R-250 or blotted to nitrocellulose membrane and detected with antiHis antibodies.

Live fluorescence microscopy - M.tb strain H37Rv constitutively expressing mCherry was grown to the exponential phase in $7 \mathrm{H} 9$ media supplemented with $10 \%$ OADC $0.5 \%$ glycerol and an aliquot was plated on glass bottom $35 \mathrm{~mm}$ petri dishes (ibidi). After 10 minutes, the liquid was removed to leave a thin lawn of cells. Next, $7 \mathrm{H} 9$ media containing $0.2 \%$ Noble agar and Coum-TAC $(0,5 \mu \mathrm{g} / \mathrm{ml})$ was overlaid on top of cells and left to solidify for 45 minutes at room temperature. The specimen was mounted on a Andor/Olympus spinning disk microscope equipped with a emCCD camera (Andor iXon Life 888) and kept at $37^{\circ} \mathrm{C}$ for time-lapse imaging. To follow Coum-TAC incorporation overtime, a Z-stack (step $355 \mathrm{~nm}$ ) was acquired every 15 min for two channels (525/40 and 607/36) with an Olympus 60x $N A=1.35$ objective. The profile of Coum-TAC incorporation was evaluated by drawing a line at the longest length of the cell, defined by mCherry fluorescence.

Lattice-SIM microscopy - M.tb strain H37Rv constitutively expressing mCherry was grown to the exponential phase in $7 \mathrm{H} 9$ media supplemented with $10 \%$ OADC $0.5 \%$ glycerol and Coum-TAC, C2 or coumarin 466 were added at a concentration of $0.5 \mu \mathrm{g} / \mathrm{mL}$. 18 hours later, each bacteria suspension was washed in PBS tween $0.05 \%$ and fixed for 2 hours in PFA $4 \%$. An aliquot of the suspension was placed on a slide and included in Prolong Glass mounting media. Incorporation of compounds was quantified using a Zeiss Elyra 7 Lattice- 
SIM microscope with a Zeiss $63 \times \mathrm{NA}=1.4$ objective and image analysis was performed in acquired $Z$ stacks using MicrobeJ plugin ${ }^{48}$ in ImageJ Software. More precisely, mCherry fluorescence of $M$.tb is used to generate a smoothed particle contour of the bacili using a skeletonization algorithm. Next, medial axes are generated from the particle contour and intensity profiles calculated from the first pole $\left(P_{0}\right)$ to the opposing pole at regular intervals $\left(P_{x}\right)$. More than 100 individual bacteria were quantified per condition.

\section{ACKNOWLEDGMENTS}

This research was supported by i) the Centre National de la Recherche Scientifique (CNRS) and the University of Toulouse (M.D., F.G., C.C., A. P., C.L., S.C.), ii) the Italian Ministry of Education, University and Research (MIUR): Dipartimenti di Eccellenza Program (20182022) - Dept. of Biology and Biotechnology "L. Spallanzani", University of Pavia (L.R.C., G.D., M.F., M.R.P.), iii) the Ministry of Education, Science, Research and Sport of the Slovak Republic, VEGA 1/0301/18 (J.K.), iv) the Slovak Research and Development Agency, APVV15-0515 (J.K.) and v) the National Institute of Allergy and Infectious Diseases/National Institutes of Health grant Al130929 (M.J.). The content is solely the responsibility of the authors and does not necessarily represent the official view of the NIH. A.F. thanks the Université de Sfax (Tunisia) for financial support. Finally, we gratefully acknowledge i) the TRI-IPBS Imaging Core Facility, member of TRI and Genotoul as well as the support of the Occitanie Region and the Fonds Européen de DEveloppement Régional (FEDER) through the 'Plateformes régionales de recherche et d'innovation' program, and ii) the Institut de Chimie de Toulouse, in particular Nathalie SAFFON, for their technical support.

\section{ABBREVIATIONS - to check}

TB, Tuberculosis; M.tb, Mycobacterium tuberculosis; INH, isoniazid; RIF, rifampicin; EMB, ethambutol; PYR, pyrazinamide; ETH, ethionamide; ISO, isoxyl; Mas, mycolic acids; FAS, fatty-acid synthase; ACP, acyl-carrier-protein; TAC, thiacetazone; MIC, minimum inhibitory concentration; HIV, human immunodeficiency virus; Ac, acetyl; DMF, $(N, N)$ dimethylformamide; LC/MS, liquid chromatography/mass spectrometry; $\mathrm{Cl}$, clinical isolate; FAD, flavin adenine dinucleotide; DprE1, decaprenyl-phosphoribose-2'-epimerase; DPR, decaprenylphosphoryl- $\beta$ - $D$-ribose; DprE2, decaprenyl-phospho-2'-keto-D-arabinose reductase; DPX, decaprenyl-phosphoryl-2'-keto-D-erythro-pentofuranose; RND, resistance, nodulation and division; DNA, deoxyribonucleic acid; ATP, adenosine triphosphate; NADPH, nicotinamide adenine dinucleotide phosphate; SD, standard deviation; OD, optical density; TLC, thin layer chromatography; TMM, trehalose monomycolates; TDM, trehalose dimycolates; FAME, fatty acid methyl esters; MAME, mycolic acid methyl esters; PE, phosphatidylethanolamine; CL, cardiolipin; SDS-PAGE, sodium dodecyl sulfatepolyacrylamide gel electrophoresis; Cys, cysteine; His, histidine; Ni-NTA, nickel-nitrilotriacetic acid; UV-vis, ultra-violet visible; EtOAc, ethyl acetate; EtOH, ethanol; M.p., melting point; IR, infrared; NMR, nuclear magnetic resonance; ESI, electrospray ionization; DMSO, dimethyl sulfoxide; FTIR-ATR, Fourier transform infrared-attenuated total reflectance; OADC, oleic acid-albumin-dextrose-catalase; BSA, bovine serum albumin; PBS, phosphate-buffered saline; MS, mass spectrometry. 


\section{REFERENCES}

(1) GBD Tuberculosis Collaborators. (2018) Global, regional, and national burden of tuberculosis, 1990-2016: results from the Global Burden of Diseases, Injuries, and Risk Factors Study. Lancet Infect. Dis. 8, 1329-1349.

(2) Grobusch, M. P. and Kapata, N. (2018) Global burden of tuberculosis: where we are and what to do. Lancet Infect. Dis. 18, 1291-1293.

(3) Vilchèze, C., Morbidoni, H. R., Weisbrod, T. R., Iwamoto, H., Kuo, M., Sacchettini, J. C., Jacobs, W. R. (2000) Inactivation of the inhA-encoded fatty acid synthase II (FAS-II) enoyl-acyl carrier protein reductase induces accumulation of the FAS-I end products and cell lysis of Mycobacterium smegmatis. J. Bacteriol. 182, 4059-4067.

(4) Sacco, E., Covarrubias, A. S., O'Hare, H. M., Carroll, P., Eynard, N., Jones, T.A., Parish, T., Daffé, M., Bäckbro, K., and Quémard, A. (2007) The missing piece of the type II fatty acid synthase system from Mycobacterium tuberculosis. Proc. Natl. Acad. Sci. U. S. A. 104, 1462814633.

(5) Slama, N., Jamet, S., Frigui, W., Pawlik, A., Bottai, D., Laval, F., Constant, P., Lemassu, A., Cam, K., Daffé, M. Brosch, R., Eynard, N., and Quémard, A. (2016) The changes in mycolic acid structures caused by hadC mutation have a dramatic effect on the virulence of Mycobacterium tuberculosis. Mol. microbial. 99, 794-807.

(6) DeBarber, A. E., Mdluli, K., Bosman, M., Bekker, L. G., and Barry, C. E., 3rd (2000) Ethionamide activation and sensitivity in multidrug- resistant Mycobacterium tuberculosis. Proc. Natl. Acad. Sci. U. S. A. 97, 9677-9682.

(7) Qian, L., and Ortiz de Montellano, P. R. (2006) Oxidative activation of thiacetazone by the Mycobacterium tuberculosis flavin monooxygenase EtaA and human FMO1 and FMO3. Chem. Res. Toxicol. 19, 443-449.

(8) Dover, L. G., Alahari, A., Gratraud, P., Gomes, J. M., Blowruth, V., Reynolds, R. C., Besra, G. S., and Kremer, L. (2007) EthA, a common activator of thiocarbamide-containing drugs acting on different mycobacterial targets. Antimicrob. Agents Chemother. 51, 1055-1063.

(9) Korduláková, J., Janin,Y. L., Liav, A., Barilone, N., DosVultos, T., Rauzier, J., Brennan, P. J., Gicquel, B., and Jackson, M. (2007) Isoxyl activation is required for bacteriostatic activity against Mycobacterium tuberculosis. Antimicrob. Agents Chemother. 51, 3824-3829.

(10) Wang, F., Langley, R., Gulten, G., Dover, L. G., Besra, G. S., Jacobs, W. R., Jr., and Sacchettini, J. C. (2007) Mechanism of thioamide drug action against tuberculosis and leprosy. J. Exp. Med. 204, 73-78.

(11) Grzegorzewicz, A. E., Eynard, N., Quemard, A., North, E. J., Margolis, A., Lindenberger, J. J., Jones, V., Kordulakova, J., Brennan, P. J., Lee, R. E., Ronning, D. R., McNeil, M. R., and Jackson, M. (2015) Covalent modification of the Mycobacterium tuberculosis FAS-II dehydratase by Isoxyl and Thiacetazone. ACS Infect. Dis. 1, 91-97. 
(12) Carel, C., Nukdee, K., Cantaloube, S., Bonne, M., Diagne, C. T., Laval, F., Daffé, M., and Zerbib, D., (2014) Mycobacterium tuberculosis proteins involved in mycolic acid synthesis and transport localize dynamically to the old growing pole and septum. PloS One 9 (5), e97148.

(13) Coxon, G. D., Craig, D., Corrales, R. M., Vialla, E., Gannoun-Zaki, L., and Kremer, L. (2013) Synthesis, antitubercular activity and mechanism of resistance of highly effective thiacetazone analogues. PLoS One 8, e53162.

(14) Halloum, I., Viljoen, A., Khanna, V., Craig, D., Bouchier, C., Brosch, R., Coxon, G., Kremer, L. (2017) Resistance to thiacetazone derivatives active against Mycobacterium abscessus involves mutations in the MmpL5 Transcriptional Repressor MAB_4384. Antimicrob. Agents Chemother. 61, e02509-e02516.

(15) Alahari, A., Trivelli, X., Guérardel, Y., Dover, L. G., Besra, G. S., Sacchettini, J. C., Reynolds, R. C., Coxon, G. D., and Kremer, L. (2007) Thiacetazone, an antitubercular drug that inhibits cyclopropanation of cell wall mycolic acids in mycobacteria. PLoS One 2 (12), e1343.

(16) (a) Sabnis, R. W. (2015) Handbook of fluorescent dyes and probes, Wiley, Oboken, NJ; (b) Wagner, B. D. (2009) The use of coumarins as environmentally-sensitive fluorescent probes of heterogeneous inclusion systems. Molecules 14, 210-237; (c) Zabradink, M. (1992) The production and application of fluorescent brightening agents, Wiley, New York.

(17) Coumarin 466 is commercially available and sold as popular fluorescent label.

(18) For reviews/books dealing with the coumarin scaffold as a relevant pharmacophore, see: (a) Stefanachi, A., Leonetti, F., Pisani, L., Catto, M., and Carotti, A. (2018) Coumarin: a natural, privileged and versatile scaffold for bioactive compounds. Molecules 23, E250; (b) Ren, Q., Gao, C., Xu, Z., Yu, Y., Liu, M. L., Wu, X., Guan, J. G., Feng, L. (2018) Bis-coumarin derivatives and their biological activities. Curr. Top. Med. Chem. 18, 101-113; (c) Hu, Y. Q., Xu, Z., Zhang, S., Wu, X., Ding, J. W., Lv, Z. S., and Feng, L. S. (2017) Recent developments of coumarincontaining derivatives and their anti-tubercular activity. Eur. J. Med. Chem. 136, 122-130; (d) Keri, R. S., Sasidhar, B. S., Nagaraja, B. M., and Santos, M. A. (2015) Recent progress in the drug development of coumarin derivatives as potent antituberculosis agents. Eur. J. Med. Chem. 100, 257-269; (e) Sandhu, S., Bansal, Y., Silakari, O., and Bansal, G. (2014) Coumarin hybrids as novel therapeutic agents. Biooorg. Med. Chem. 22, 3806-3814; (f) Penta, S. (2016) Advances in structure and activity relationship of coumarin derivatives, Academic Press, Oxford.

(19) (a) Suparji, N. S., Chan, G., Sapili, H., Arshad, N. M., In, L. L. A., Awang, K., and Nagoor, N. H. (2016) Geranylated 4-phenylcoumarins exhibit anticancer effects against human prostate cancer cells through caspase-independent mechanism. PLoS One. 11, e0151472; (b)

Galayev, O., Garazd, Y., Garazd, M., and Lesyk, R. Synthesis and anticancer activity of 6heteroarylcoumarins. Eur. J. Med. Chem. 2015, 105, 171-181; (c) Donnelly, A. C., Mays, J. R., Burlison, J. A., Nelson, J. T., Vielhauer, G., Holzbeierlein, J., and Blagg, B. S. J. (2008) The design, synthesis and evaluation of coumarin ring derivatives of the novobiocin scaffold that exhibit anti-proliferative activity J. Org. Chem. 73, 8901-8920; (d) Thakur, A., Singla, R., and Jaitak, V. (2015) Coumarins as anticancer agents: a review on synthetic strategies, mechanism of action and SAR studies. Eur. J. Med. Chem. 101, 476-495.

(20) (a) Sashidhara, K. V., Modukuri, R. K., Singh, S., Bhaskara Rao, K., Aruna Teja, G., Gupta, S., and Shukla, S. (2015) Design and synthesis of new series of coumarin-aminopyran derivatives possessing potential anti-depressant-like activity. Bioorg. Med. Chem. Lett. 25 (2), 337-341; (b) Sashidhara, K. V., Rao, K. B., Singh, S, Modukuri, R. K., Aruna Teja, G., 
Chandasana, H., Shukla, S., and Bhatta, R. S. (2014) Synthesis and evaluation of new 3phenylcoumarin derivatives as potential antidepressant agents. Bioorg. Med. Chem. Lett. 24, 4876-4880.

(21) (a) Shaik, J. B., Palaka, B. K., Penumala, M., Kotapati, K. V., Devineni, S. R., Eadlapalli, S. Darla, M. M., Ampasala, D. R., Vadde, R., and Amooru, G. D. (2016) Synthesis, pharmacological assessment, molecular modeling and in silico studies of fused tricyclic coumarin derivatives as a new family of multifunctional anti-Alzheimer agents. Eur. J. Med. Chem. 107, 219-232. (b) Huang, M., Xie, S. S., Jiang, N., Lan, J. S., Kong, L. Y., and Wang, X. B. (2015) Multifunctional coumarin derivatives: monoamine oxidase $B$ (MAO-B) inhibition, anti- $\beta$-amyloid $(A \beta)$ aggregation and metal chelation properties against Alzheimer's disease. Bioorg. Med. Chem. Lett. 25, 508-513.

(22) Pu, W., Lin, Y., Zhang, J., Wang, F., Wang, C., Zhang, G. (2014) 3-Arylcoumarins: synthesis and potent anti-inflammatory activity. Bioorg. Med. Chem. Lett. 24(23), 5432-5434.

(23) Martinčič, R., Mravljak, J., Švajger, U., Perdih, A., Anderluh, M., and Novič, M. (2015) In Silico Discovery of novel potent antioxidants on the basis of pulvinic acid and coumarin derivatives and their experimental evaluation. PLoS One 10, e0140602.

(24) (a) Kudo, E., Taura, M., Matsuda, K., Shimamoto, M., Kariya, R., Goto, H., Hattori, S., Kimura, S., and Okada, S. (2013) Inhibition of HIV-1 replication by a tricyclic coumarin GUT-70 in acutely and chronically infected cells. Bioorg. Med. Chem. Lett. 23, 606-609; (b) Boon Beng Ong, E., Watanabe, N., Saito, A., Futamura, Y., Abd El Galil, K. H., Koito, A., and Najimudin, N., and Osada, H. (2011) Vipirinin, a coumarin-based HIV-1 Vpr Inhibitor, interacts with a hydrophobic region of VPR. J. Biol. Chem. 286, 14049-14056.

(25) (a) Xy, Z.-Q., Barrow, W. W., Suling, W. J., Westbrook, L., Barrow, E., Lin, Y.-M., and Flavi,n M. T. (2004) Anti-HIV natural product (+)-calanolide A is active against both drug-susceptible and drug-resistant strains of Mycobacterium tuberculosis. Bioorg. Med. Chem. 12, 1199-1207; (b) Stanley, S. A., Kawate, T., Iwase, N., Shimizu, M., Clatworthy, A. E., Kazyanskaya, E., Sacchettini, J. C., loerger, T. R., Siddiqi, N. A., Minami, S., Aquadro, J. A., Grant, S. S., Rubin, E. J., and Hung, D. T. (2013) Diarylcoumarins inhibit mycolic acid biosynthesis and kill Mycobacterium tuberculosis by targeting FadD32. Proc. Natl. Acad. Sci. USA 110, 11565-11570; (c) Manvar, A., Malde, A., Verma, J., Virsodia, V., Mishra, A., Upadhyay, K., Acharya, H., Coutinho, E., and Shah A. (2008) Synthesis, an ti-tubercular activity and 3D-QSAR study of coumarin-4-acetic acid benzylidene hydrazides. Eur. J. Med. Chem. 43, 2395-2403; (d) Manvar, A., Bavishi, A., Radadiya, A., Patel, J., Vora, V., Dodia, N., Rawal, K., and Shah, A. (2011) Diversity oriented design of various hydrazides and their in vitro evaluation against Mycobacterium tuberculosis H37Rv strains. Bioorg. Med. Chem. Lett. 21, 4728-4731; (e) V. Virsodia, V., Shaikh, M. S., Manvar, A., Desai, B., Parecha, A., Loriya, R., Dholariya, K., Patel, G., Vora, V., Upadhyay, K., Denish, K., Shah, A., and Coutinho, E. C. (2010) Screening for in vitro antimycobacterial activity and three-dimensional quantitative structure-activity relationship (3D-QSAR) study of 4-(arylamino)coumarin derivatives. Chem. Biol. Drug Des. 76, 412-424; (f) Angelova, V. T., Valcheva, V., Vassilev, N. G., Buyukliev, R., Momekov, G., Dimitrov, I., Saso, L., Djukic, M., and Shivachev, B. (2017) Antimycobacterial activity of novel hydrazide-hydrazone derivatives with $2 \mathrm{H}$-chromene and coumarin scaffold. Bioorg. Med. Chem. Lett. 27, 223-227.

(26) Carrère-Kremer, S., Blaise, M., Singh, V. K., Alibaud, L., Tuaillon, E., Halloum, I., van de Weerd, R., Guérardel, Y., Drancourt, M., Takiff, H., Geurtsen, J., Kremer, L. (2015) A new 
dehydratase conferring innate resistance to thiacetazone and intra-amoebal survival of Mycobacterium smegmatis. Mol. Microbiol. 96, 1085-1102.

(27) Albesa-Jové, D., Chiarelli, L. R., Makarov, V., Pasca, M. R., Urresti, S., Mori, G., Salina, E., Vocat, A., Comino, N., Mohorko, E., Ryabova, S., Pfieiffer, B., Lopes Ribeiro, A. L., RodrigoUnzueta, A., Tersa, M., Zanoni, G., Buroni, S., Altmann, K. H., Hartkoorn, R. C., Glockshuber, R., Cole, S. T., Riccardi, G., and Guerin, M. E. (2014) Rv2466c mediates the activation of TP053 to kill replicating and non-replicating Mycobacterium tuberculosis. ACS Chem. Biol. 9 (7), 15671575.

(28) Makarov V., Manina, G., Mikusova, K., Möllmann, U., Ryabova, O., Saint-Joanis, B., Dhar, N., Pasca, M. R., Buroni, S., Lucarelli, A. P., Milano, A., De Rossi, E., Belanova, M., Bobovska, A., Dianiskova, P., Kordulakova, J., Sala, C., Fullam, E., Schneider, P., McKinney, J. D., Brodin, P., Christophe, T., Waddell, S., Butcher, P., Albrethsen, J., Rosenkrands, I., Brosch, R., Nandi, V., Bharath, S., Gaonkar, S., Shandil, R. K., Balasubramanian, V., Balganesh, T., Tyagi, S., Grosset, J., Riccardi, G., and Cole, S. T. (2009) Benzothiazinones kill Mycobacterium tuberculosis by blocking arabinan synthesis. Science 324 (5928), 801-804.

(29) Poce, G., Bates, R. H., Alfonso, S., Cocozza, M., Porretta, G. C., Ballell, L., Rullas, J., Ortega, F., De Logu, A., Agus, E., La Rosa, V., Pasca, M. R., De Rossi, E., Wae, B., Franzblau, S. G., Manetti, F., Botta, M. and Biava, M. (2013) Improved BM212 MmpL3 inhibitor analogue shows efficacy in acute murine model of tuberculosis infection. PLoS One. 8 (2), e56980.

(30) Neres, J., Hartkoorn, R. C., Chiarelli, L. R., Gadupudi, R., Pasca, M. R., Mori, G., Venturelli, A., Savina, S., Makarov, V., Kolly, G. S., Molteni, E., Binda, C., Dhar, N., Ferrari, S., Brodin, P., Delorme, V., Landry, V., de Jesus Lopes Ribeiro, A. L., Farina, D., Saxena, P., Pojer, F., Carta, A., Luciani, R., Porta A., Zanoni G., De Rossi E., Costi M. P., Riccardi G., and Cole, S. T. (2015) 2-Carboxyquinoxalines kill Mycobacterium tuberculosis through noncovalent inhibition of DrpE1. ACS Chem Biol. 10 (3), 705-714.

(31) Chiarelli, L. R., Mori, G., Orena, B. S., Esposito, M., Lane, M., de Jesus Lopes Ribeiro, A. L., Degiacomi, G., Zemanova, G., Szadocka, S., Huszar, S., Palcekova, Manfredi, M., Gosetti, F., Lelièvre, J., Ballell, L., Kazakova, E., Makarov, V., Marengo, E., Mikusova, K., Cole, S. T., Riccardi, G., Ekins, S., and Pasca M. R. (2018) A multitarget approach to drug discovery inhibiting Mycobacterium tuberculosis PyrG and PanK. Sc. Rep. 8, 3187.

(32) Mori, G., Chiarelli, L. R., Esposito, M., Makarov, V., Bellinzoni, M., Hartkoorn, R. C., Degiacomi, G., Boldrin, F., Ekins, E., de Jesus Lopes Ribeiro, A. L., Marino, L. B. , Centárová, I., Svetlíková, Z., Blaško, J., Kazakova, E., Lepioshkin, A., Barilone, N., Zanoni, G., Porta, A., Fondi, M., Fani, R., Baulard, A. R., Mikušová, K., Alzari, P. M., Manganelli, R., de Carvalho, L. P., Riccardi, G., Cole, S. T., and Pasca, M. R. (2015) Thiophenecarboxamide derivatives activated by EthA kill Mycobacterium tuberculosis by inhibiting the CTP synthase PyrG. Chem. Biol. 22, 917-927.

(33) Degiacomi, G., Sammartino, J. C., Sinigiani, V., Marra, P., Urbani, A., Pasca, M. R. (2020) In vitro study of Bedaquiline resistance in Mycobacterium tuberculosis multi-drug resistant clinical isolates. Front Microbiol. 11:559469.

(34) Grzegorzewicz, A. E., Kordulakova, J., Jones, V., Born, S. E., Belardinelli, J. M., Vaquie, A., Gundi, V. A., Madacki, J., Slama, N., Laval, F., Vaubourgeix, J., Crew, R. M., Gicquel, B., Daffe, M., Morbidoni, H. R., Brennan, P. J., Quemard, A., McNeil, M. R., and Jackson, M. (2012) A 
common mechanism of inhibition of the Mycobacterium tuberculosis mycolic acid biosynthetic pathway by isoxyl and thiacetazone. J. Biol. Chem. 287, 38434-38441.

(35) For live imaging of the real-time incorporation of Coum-TAC into M.tb strain H37Rv, see the Movie given as Supplementary Materials.

(36) Betzig, E. (2005) Excital strategies for optical lattice microscopy. Opt. Express. 13, 30213036.

(37) Dewachter, L., Fauvart, M., Michiels, J. (2019) Bacterial heterogeneity and antibiotic survival: understanding and combatting persistence and heteroresistance. Mol. Cell 17, 255-267.

(38) Ackermann, M. (2015) A functional perspective on phenotypic heterogeneity in microorganisms. Nat. Rev. Microbiol. 13, 497-508.

(39) CCDC1998723 for compound 3 contains the supplementary data for this paper. These data can be obtained free of charge from The Cambridge Crystallographic Data Centre via https://www.ccdc.cam.ac.uk/structures/?.

(40) Selected data for compound $3: \mathrm{C}_{18} \mathrm{H}_{17} \mathrm{NO}_{3} \mathrm{~S}, M=327.38$, monoclinic, space group $P 2_{1} / c$, a $=13.441$ (3) $\AA, b=12.660$ (3) $\AA, c=9.421(2) \AA, \beta=105.759(7)^{\circ}, V=1542.9(6) \AA^{3}, Z=4$, crystal size $0.20 \times 0.02 \times 0.02 \mathrm{~mm}^{3}, 35538$ reflections collected (2689 independent, Rint $=0.1700$ ), 210 parameters, $R 1[\mathrm{l}>2 \mathrm{~s}(\mathrm{I})]=0.0485, w R 2$ [all data] $=0.1215$, largest diff. peak and hole: 0.211 and $0.230 \mathrm{e}^{-3}$.

(41) Bruker, SADABS, Bruker AXS Inc., Madison, Wisconsin, USA, 2008.

(42) Sheldrick G. M. (2015) SHELXT - Integrated space-group and crystal-structure determination. Acta Crystallogr. Sect. A 71, 3-8.

(43) Ordonez-Hernandez, J., Jimenez-Sanchez, A., Garcia-Ortega, H., Sanchez-Puig, N., FloresAlamo, M., Santillan, R., and Farfan, N. (2018) A series of dual-responsive Coumarin-Bodipy probes for local microviscosity monitoring. Dyes Pigm. 157, 305-313.

(44) Liang, H., Xue, Z., Qing, Y., Yujin, L., and Jianrong, G. (2013) Synthesis and photoelectric properties of coumarin type sensitizing dyes. Chin. J. Org. Chem. 33, 1000-1004.

(45) Folch, J., Lees, M., and Sloane Stanley, G. H. (1957) A simple method for the isolation and purification of total lipids from animal tissues. J. Biol. Chem. 226, 497-509.

(46) Phetsuksiri, B., Baulard, A. R., Cooper, A. M., Minnikin, D. E., Douglas, J. D., Besra, G. S., and Brennan, P. J. (1999) Antimycobacterial activities of isoxyl and new derivatives through the inhibition of mycolic acid synthesis. Antimicrob. Agents Chemother. 43, 1042-1051.

(47) Triccas, J. A., Parish, T., Britton, W. J., and Gicquel, B. (1998) An inducible expression system permitting the efficient purification of a recombinant antigen from Mycobacterium smegmatis. FEMS Microbiol. Lett. 167, 151-156.

(48) Ducret, A., Quardokus, E. M., Brun, Y. V. (2016) MicrobeJ, a tool for high throughput bacterial cell detection and quantitative analysis. Nat. Microbiol. 1, 1-7.

\section{GRAPHICAL ABSTRACT}



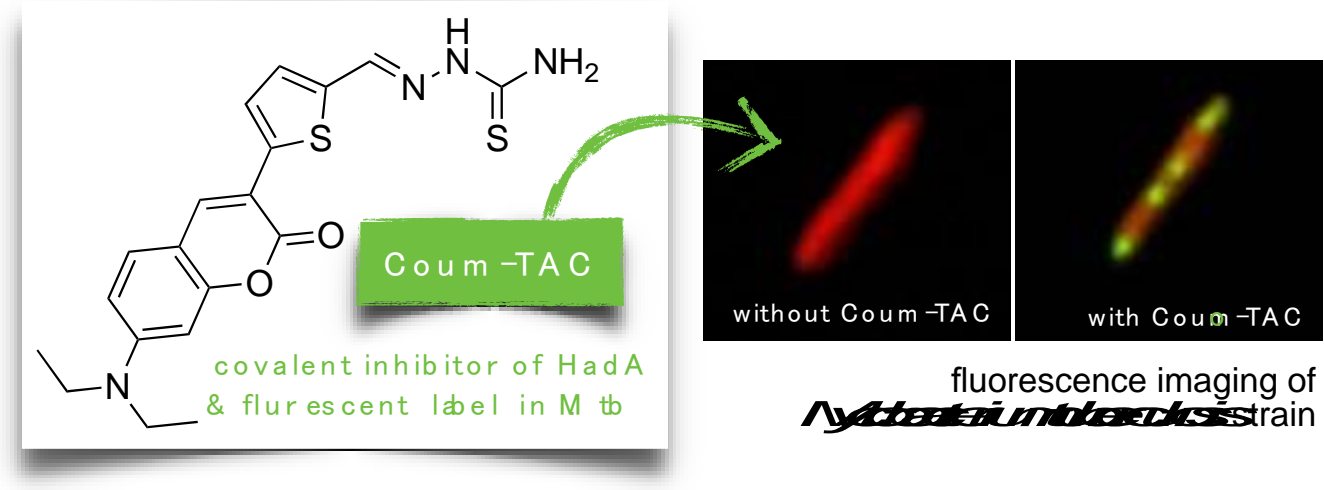

\section{RESUME}

In this work is reported the rational design, synthesis, antitubercular evaluation and imaging potential of a small and easy-to-prepare molecule playing the dual role of i) efficient inhibitor of a relevant therapeutic target, namely HadA, to combat Mycobacterium tuberculosis, and ii) fluorescent probe to selectively label M.tb and get insights for the first time on the localization of HadA in the mycobacteria. 